\title{
A Comprehensive Review: Materials for the Fabrication of Optical Fiber Refractometers Based on Lossy Mode Resonance
}

\author{
Aritz Ozcariz ${ }^{1, * \mathbb{C}}$, Carlos Ruiz-Zamarreño ${ }^{1,2}$ (i) and Francisco J. Arregui ${ }^{1,2} \mathbb{C}$ \\ 1 Department of Electric, Electronic and Communication Engineering, Public University of Navarre, \\ E-31006 Pamplona, Spain; carlos.ruiz@unavarra.es (C.R.-Z); parregui@unavarra.es (F.J.A) \\ 2 Institute of Smart Cities (ISC), Public University of Navarre, E-31006 Pamplona, Spain \\ * Correspondence: aritz.ozcariz@unavarra.es; Tel.: +34 948169841
}

Received: 14 March 2020; Accepted: 30 March 2020; Published: 1 April 2020

check for updates

\begin{abstract}
Lossy mode resonance based sensors have been extensively studied in recent years. The versatility of the lossy mode resonance phenomenon has led to the development of sensors based on different configurations that make use of a wide range of materials. The coating material is one of the key elements in the performance of a refractometer. This review paper intends to provide a global view of the wide range of coating materials available for the development of lossy mode resonance based refractometers.
\end{abstract}

Keywords: optical fiber sensor; optical sensor; LMR; lossy mode resonance

\section{Introduction}

Sensors have acquired an unprecedented presence in modern society. In industry, medicine, and even in our own homes, we are increasingly relying on a number of sensors to achieve a safer environment and a healthier and more comfortable life [1-4]. As this field evolves, new mechanisms and configurations are researched, which facilitate the development of better sensors and new applications.

The versatility and practicality of optical fibers makes them a great base for the fabrication of sensors. In fact, there is a wide range of mechanisms that allow the fabrication of sensors using optical fibers. This review paper will discuss one type that has already proven to be capable of achieve astonishing performance-lossy mode resonance (LMR) fibers. LMR occurs due to the interaction of the light propagating through a waveguide coated with a film of appropriate optical properties. If the coating possesses certain properties (detailed below), the waveguide modes may couple to the coating modes, generating a lossy mode. This effect causes an absorption peak at the wavelength at which the conditions are fulfilled. This resonance should not be confused with surface plasmon resonance (SPR), which can also be observed in waveguides with certain coatings, since they are two separate phenomena. SPR is generated at metal-dielectric interfaces, which are typically obtained with conductive thin films, such as gold [5], whereas the LMR conditions enable the use of a larger range of materials [6]. LMR can be supported by the fabrication of films made of different materials, such as indium tin oxide (ITO) [7], zinc oxide [8], polymers [9], or silicon nitride [10], among others.

LMR will suffer a variation if either a variation in the properties of the LMR support film (either refractive index or thickness) or a change in the optical properties (refractive index) of the surrounding media occurs. Provided the coating is stable, the LMR will only be affected by the surrounding media refractive index (SRI), meaning that it is essentially a good mechanism for the development of refractometers. This mechanism can be used as the basis for the design of multiple kinds of physical and chemical sensors. An external coating, whose optical properties rely on a given parameter that 
needs to be measured, could be fabricated on top of a LMR-based refractometer, and the variation of this variable could be measured by monitoring the LMR wavelength shift. It should be noted that the development of such sensors does not rely solely on the fabrication of a functionalizing overlay. Given the number of materials capable of supporting LMR, the right choice for the composition of this coating can facilitate the fabrication of many different kinds of sensors. For instance, an ITO nanoparticle coating was used for the fabrication of a hydrogen gas sensor [7], while zinc oxide nanorods were used in the fabrication of a coating whose LMR was sensitive to sulfide gas $\left(\mathrm{H}_{2} \mathrm{~S}\right)$ [11]. On a different note, polymeric coatings of polyallylamine hydrochloride (PAH) and polyacrylic acid (PAA) were used to fabricate LMR-based $\mathrm{pH}$ [12] and relative humidity [9] sensors.

The purpose of this review is to summarize the most relevant coating materials that have been reported for the development of LMR-based sensors. We also aim to provide an overview of the results achieved with each of them and the applications proposed for each material. The study of the different coating materials presented here is a proof of the versatility and great potential of this technique, as it has a great range of applications.

\section{Basic Concepts}

A classical optical fiber is typically composed of a cylindrical core surrounded by a layer known as cladding. The lower refractive index of the cladding with respect to the core allows the light to propagate through the fiber with very low attenuation and in a way that is practically insensitive to the external conditions of the fiber, making it the ideal mechanism for transmission of optical signals over long distances. If the cladding (or a part of it) is removed in a segment of the fiber and substituted for a different material, the propagation of the light might be affected. Depending on the optical properties of the applied coating, different resonance might be excited. One of the most well-known resonances generated in this way is surface plasmon resonance (SPR), which occurs when the real part of the coating permittivity is negative and greater in magnitude than both its imaginary part and the real part of the external medium permittivity [13]. A conductor such as gold is the typical material used for the fabrication of SPR-supporting thin films. Another type of resonance that can be generated with materials of different optical properties is LMR. In order to be able to generate LMR, the coating must have a real positive permittivity part that must also be greater in magnitude than both its imaginary part and the real part of the external medium permittivity. In terms of the refractive index, this means that the chosen coating must have a relatively high real part (n) and a comparatively low (but non zero) imaginary part (k) (Figure 1).

\section{LMR and SPR generation conditions}

\begin{tabular}{|c|c|c|}
\hline TYPE OF RESONANCE & $\hat{\varepsilon}$ CONDITIONS & $\begin{array}{c}\text { n,k CONDITIONS } \\
\forall n>0, k>0\end{array}$ \\
\hline $\begin{array}{c}\text { SPR } \\
\text { Surface Plasmon } \\
\text { Resonance }\end{array}$ & $\begin{array}{c}\mathcal{E}_{2}^{\prime}<0 \\
\left|\mathcal{E}_{2}^{\prime}\right|>\left|\mathcal{E}_{2}^{\prime \prime}\right| \\
\left|\mathcal{E}_{2}^{\prime}\right|>\left|\mathcal{E}_{3}^{\prime}\right|\end{array}$ & $\begin{array}{l}k_{2}>(\sqrt{2}+1) n_{2} \\
k_{2}^{2}-n_{2}^{2}>1.45^{2}\end{array}$ \\
\hline $\begin{array}{c}\text { LMR } \\
\text { Lossy Mode } \\
\text { Resonance }\end{array}$ & $\begin{array}{c}\mathcal{E}_{2}^{\prime}>0 \\
\left|\mathcal{E}_{2}^{\prime}\right|>\left|\mathcal{E}_{2}^{\prime \prime}\right| \\
\left|\mathcal{E}_{2}^{\prime}\right|>\left|\mathcal{E}_{\mathcal{S}^{\prime}}\right|\end{array}$ & $\begin{array}{l}k_{2}<(\sqrt{2}-1) n_{2} \\
n_{2}^{2}-k_{2}^{2}>1.45^{2}\end{array}$ \\
\hline
\end{tabular}

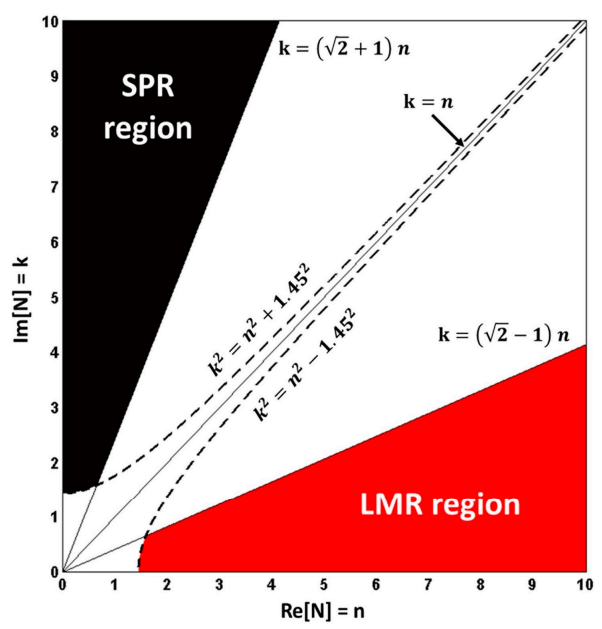

Figure 1. Optical parameters for the generation of surface plasmon resonance (SPR) and lossy mode resonance (LMR). Reprinted from [13] with permission from Elsevier. 
When LMR is generated in an optical fiber, this phenomenon can be observed as an absorption peak at a given wavelength in the transmission spectra. The location of this resonance in the spectra depends on the optical properties (refractive index) of the LMR support film, its thickness, and the surrounding media refractive index (SRI). Therefore, a variation in the SRI or in the film (either its thickness or its refractive index) will induce a shift in the wavelength of the LMR that can be measured, and is the basis for the fabrication of a number of sensors. Figure 2 shows an example of the spectra of a LMR sensor measuring different SRI values. The peak of the LMR shifts to a longer wavelength as the SRI increases and its position can be tracked, establishing a direct relation between LMR position and SRI value (inset in Figure 2). It is important to note that the sensitivity to SRI (measured as the wavelength shift in nanometers per refractive index unit, nm/RIU) is not a constant, since it increases for higher SRI values [6]. Additionally, it can be observed that an increase in the coating thickness causes the shift on the LMR to a longer wavelength, which also provokes an increase in sensitivity. It should also be noted that as the thickness increases, more LMR of higher orders appear at shorter wavelengths, and these new resonances are consecutively less sensitive than the previous one. Another factor to consider regarding the sensitivity of the LMR is the refractive index of the coating. A coating with a higher refractive index will generate a more sensitive resonance. It can be easily inferred that the appropriate choice and fabrication of this coating material will have a direct impact on the performance of the sensor.

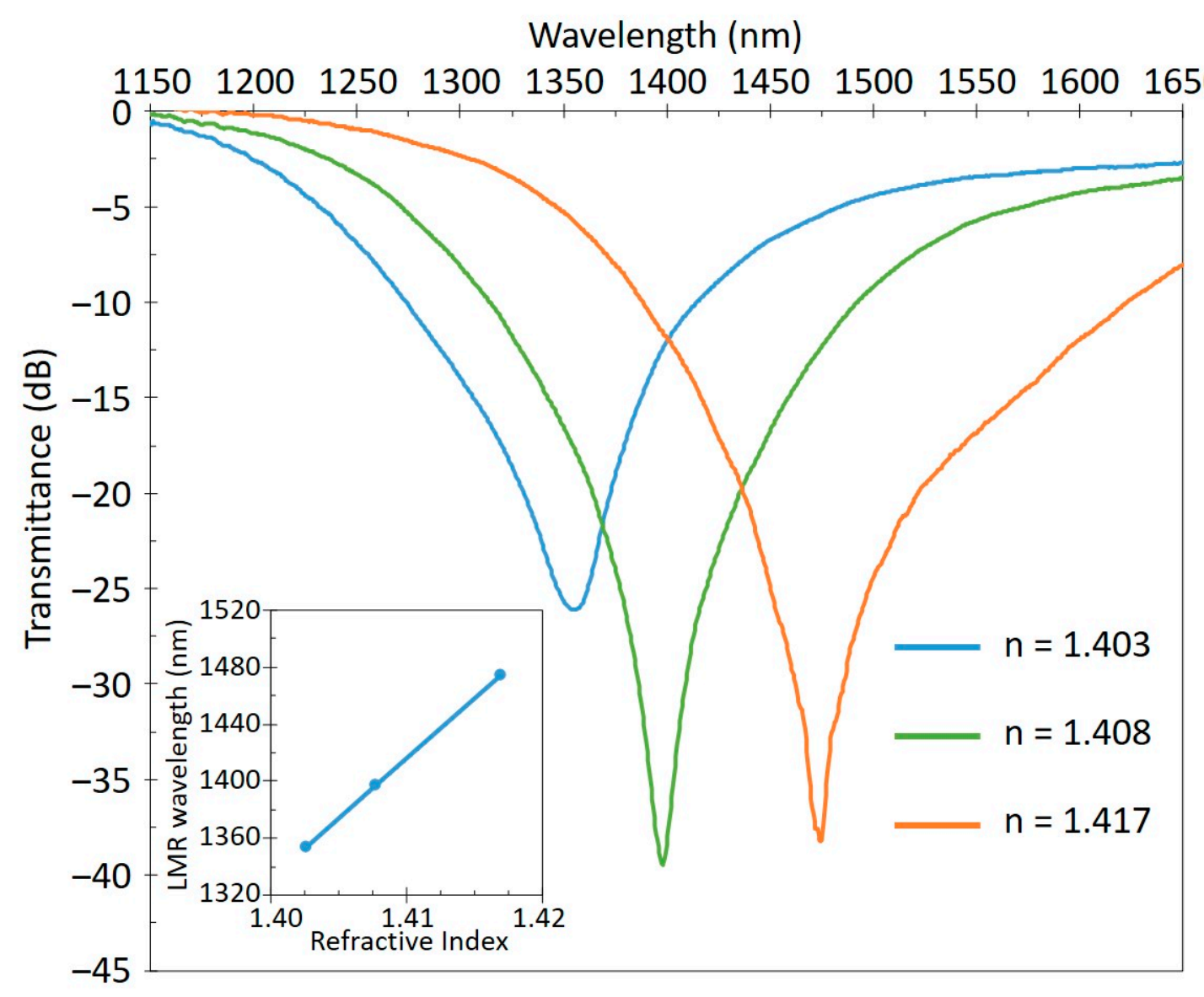

Figure 2. Example of the evolution of LMR for different surrounding media refractive index (SRI) values. The peak of the LMR shifts to longer wavelengths as the SRI increases. The inset shows a typical calibration curve, plotting the LMR position in function of the SRI, which characterizes the device as a refractometer. 


\section{Setup Configurations}

A relevant aspect to take into consideration is the architecture or setup designed for the sensor. It is important to note that LMR, unlike SPR, occurs in both transverse electric (TE) and transverse magnetic (TM) modes. These modes refer to the directions of the electric and magnetic fields in the waveguide. A TE mode has no electric field in the direction of propagation (magnetic only), while the TM mode has no magnetic field in the direction of propagation (electric field only). In order to excite a surface plasmon, the incident wave must have an electric field component parallel to the direction of propagation of the wave at the waveguide-coating interface, which is the case for the TM mode only [5]. In this way, the study of SPR requires the use of polarized light so that only the TM mode is propagated, which allows the full amplitude of the resonance to be observed. On the contrary, LMR is based on the coupling of a guided mode to a mode with losses on film, and is not limited to a single mode of propagation [6]. This provides greater flexibility in the experimental setups, as no polarization of light is needed. Therefore, a basic probe configuration for LMR sensor fabrication consists of a segment of cladding-removed multimode optical fiber (CRMOF), on top of which a high refractive index thin film is deposited [6]. The coated CRMOF is then connected to a light source and an optical spectrum analyzer (OSA) or a spectrometer in order to study the transmitted spectra (Figure 3). A similar approach using a single mode fiber (SMF) would require an etching process be applied to the fiber in order to reduce the diameter of the cladding so that the evanescent mode in the fiber could reach the later deposited LMR support coating. This process is necessary in standard SMFs because the small diameter of the core in such fibers makes it very difficult to complete the removal of the cladding, in contrast to multimode fibers (MMFs), which can be specifically fabricated so that the cladding can easily be completely removed $[6,10,11]$. Alternatively, an optical fiber could be tapered in order to reduce its diameter so that the light is guided out of the core and can interact with an outer coating. This configuration has been used in the design of reflection setups, where a tapered tip coated with a LMR support material is suggested $[14,15]$.

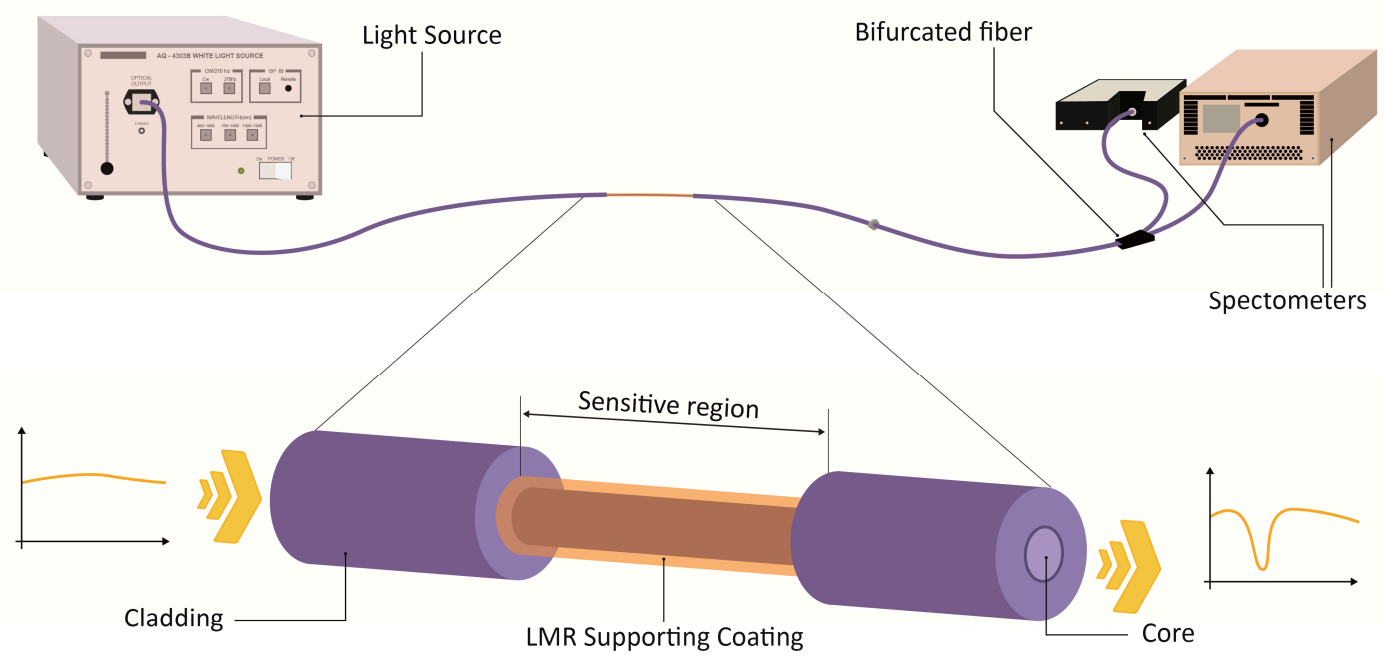

Figure 3. Typical setup involving a cladding-removed multimode optical fiber (CRMOF) for the fabrication of a LMR-based refractometer. In this case, a bifurcated fiber was included to observe a wider spectrum using two refractometers.

A more complex setup for the purpose of separating the propagation modes involves the use of polarized light and a D-shaped fiber. This kind of fiber contains a segment where a polishing process has been performed. This procedure modifies the geometry of the fiber, whose section acquires a capital " $\mathrm{D}$ " shape (hence its name). This configuration, in combination with the use of polarized light, causes the LMR to be excited only at a certain axis (the axis with the polished side), as it is the only angle where the wave reaches the outer coating. This mechanism allows the effective separation of 
LMR generated in different propagation modes. As an example, Figure 4 presents the simulation of two propagation modes in an ITO-coated D-shaped fiber [16]. It shows how the cladding mode $\mathrm{TE}_{1,1}$ (a particular TE mode observed on circular waveguides) is confined in the cladding at a wavelength of $1690 \mathrm{~nm}$, and transforms into a TE mode on the ITO layer as the wavelength decreases. It also shows how the $\mathrm{HE}_{1,1}$ (a hybrid mode where the TE component dominates over the TM) is confined in the core for all the simulated wavelengths, with the exception at $1420 \mathrm{~nm}$, where it can be seen how part of the energy couples to the ITO coating due to the LMR.

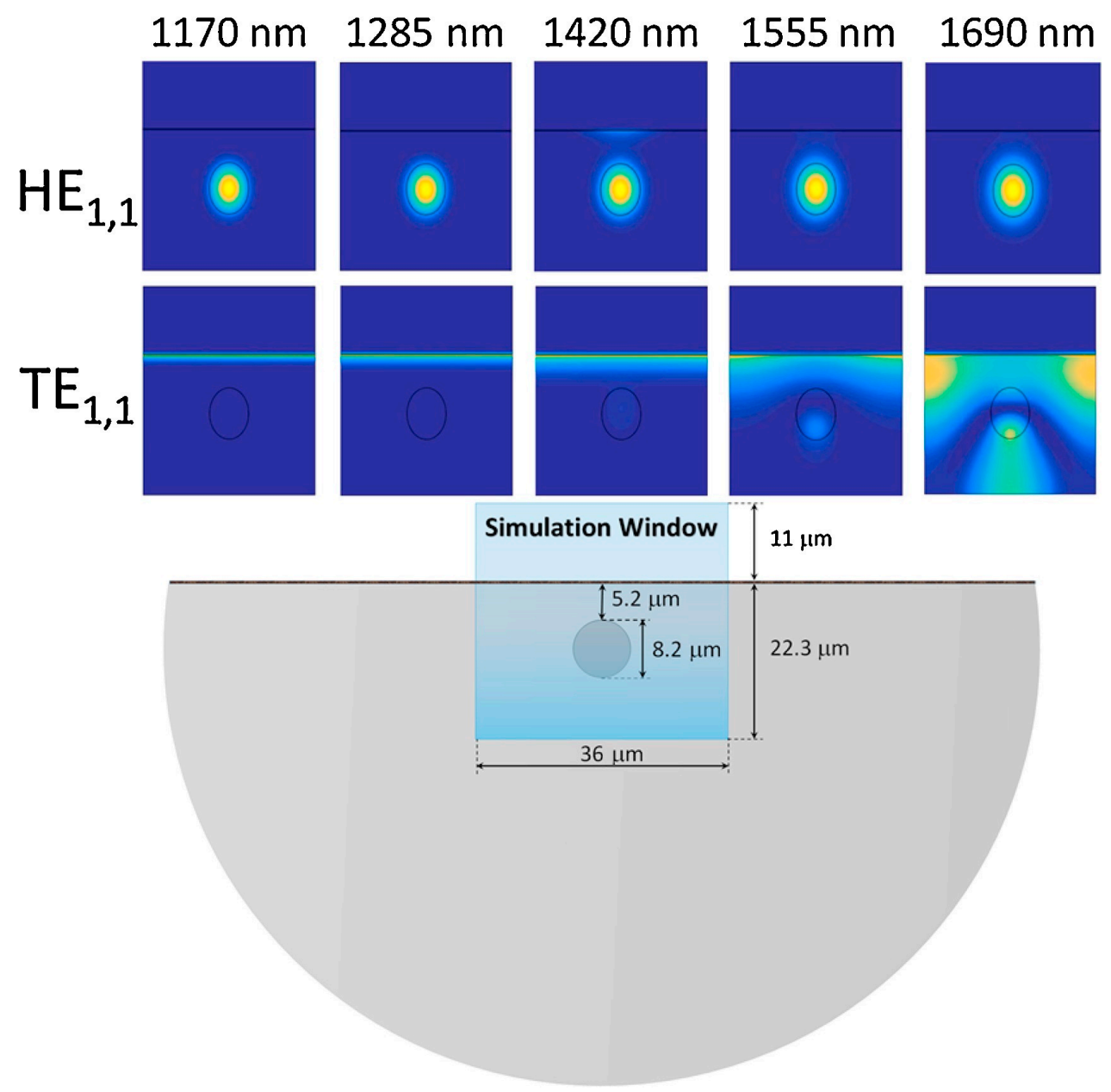

Figure 4. Schematic and simulation results of the electric field intensity in an indium tin oxide (ITO)-coated D-shaped fiber for the $\mathrm{TE}_{1,1}$ and $\mathrm{HE}_{1,1}$ modes. Reprinted from [16] with permission from Elsevier.

Another setup to consider, since it is the standard for SPR-based systems, is the Kretschmann configuration (Figure 5). This design involves the use of polarized light directed onto a coated prism at different incident angles, monitoring the reflectance power at the corresponding angle. In this case, the resonance will typically be observed as a dip at a given angle, and the SRI variations will be measured as a shift in the angle at which the said dip is measured. Alternatively, a broadband light source can be used in the same setup in order to monitor the spectra, such as in the setups explained previously.

In contrast to SPR, for which there are only a few coating materials considered appropriate for resonance generation (with gold being the standard), several materials have been successfully studied for LMR generation. Given the optical parameters required for a coating material to be able to support LMR generation, most of the research has been focused on metal oxides such as $\mathrm{SnO}_{2}, \mathrm{TiO}_{2}$, or $\mathrm{ZnO}$; however, other materials such as graphene oxide or polymer-based films have also been tested, as will 
be described in the next section. The choice of the coating material will directly affect the performance and the validity of the sensor for the target application. Accordingly, a thorough study of the different materials used for this purpose is presented, indicating the main characteristics of each coating and some of the most relevant sensors developed with them.

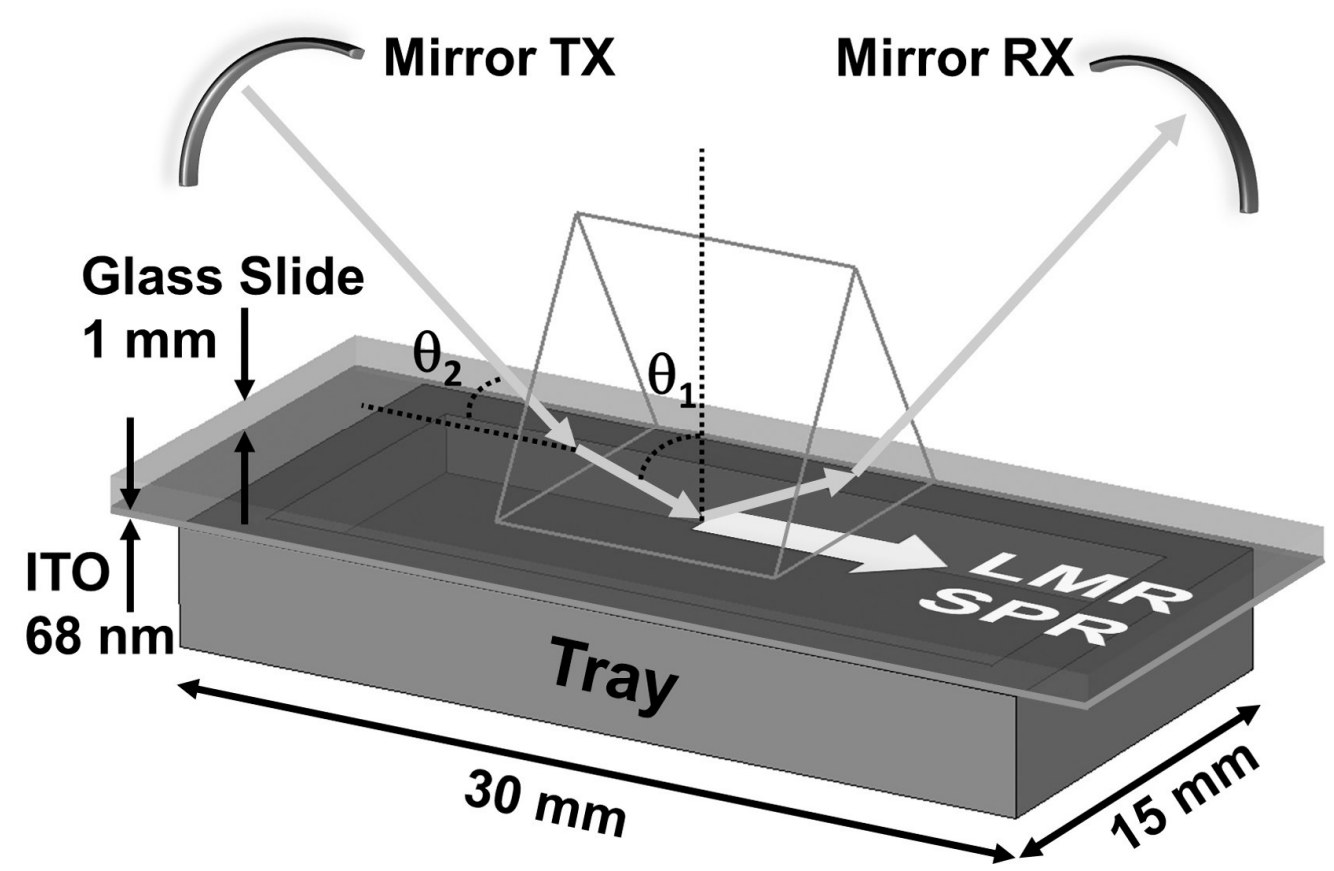

Figure 5. Example of a Kretschmann configuration for the analysis of SPR and LMR. In this case, the polarized light coming from the transmitting mirror TX is coupled through a prism to a coated glass slide so that the light beam is reflected in the interface at the desired angle $\theta_{1}$. The coated side is facing a sample tray containing the media whose refractive index is being measured. The reflected beam is collected by the receiving mirror RX. Reprinted from [17] with permission from AIP Publishing.

\section{Coating Materials}

The following sections will describe the principal characteristics of each coating and their main achievements, as well as their differences. Some of the proposed applications and their performance as sensors will also be explained. Firstly, we present the studies that made use of several metal oxides coatings. Then, we discuss different works based on polymeric films. Finally, in the last section we group the works that are based on novel materials that could not be classified as an independent category.

\subsection{Indium Tin Oxide (ITO)}

Indium tin oxide is a well-known transparent conductive oxide (TCO) that is widely used in optics and electronics. One very interesting characteristic of ITO is the fact that in can generate both LMR and SPR, as it fulfills the requisites for the generation of both resonance, with LMR being generated at lower wavelengths and SPR at wavelengths above $2000 \mathrm{~nm}$ [18] (see Figure 6). Over the last decade, several sensors using ITO as the coating material for the generation of LMR have been studied. ITO has been used on multimode fibers of different diameters [7,19,20], as well as D-shaped fibers [16,21] or glass slide in Kretschmann configuration [22]. Most authors have studied ITO as a coating material by fabricating a thin film by means of sputtering $[16,23,24]$ or thermal evaporation technique [7], however other techniques such as dip coating have also been used [19]. While most studies have been focused on homogeneous ITO thin films, some works have been reported using nanoparticle-based ITO coatings [7]. 


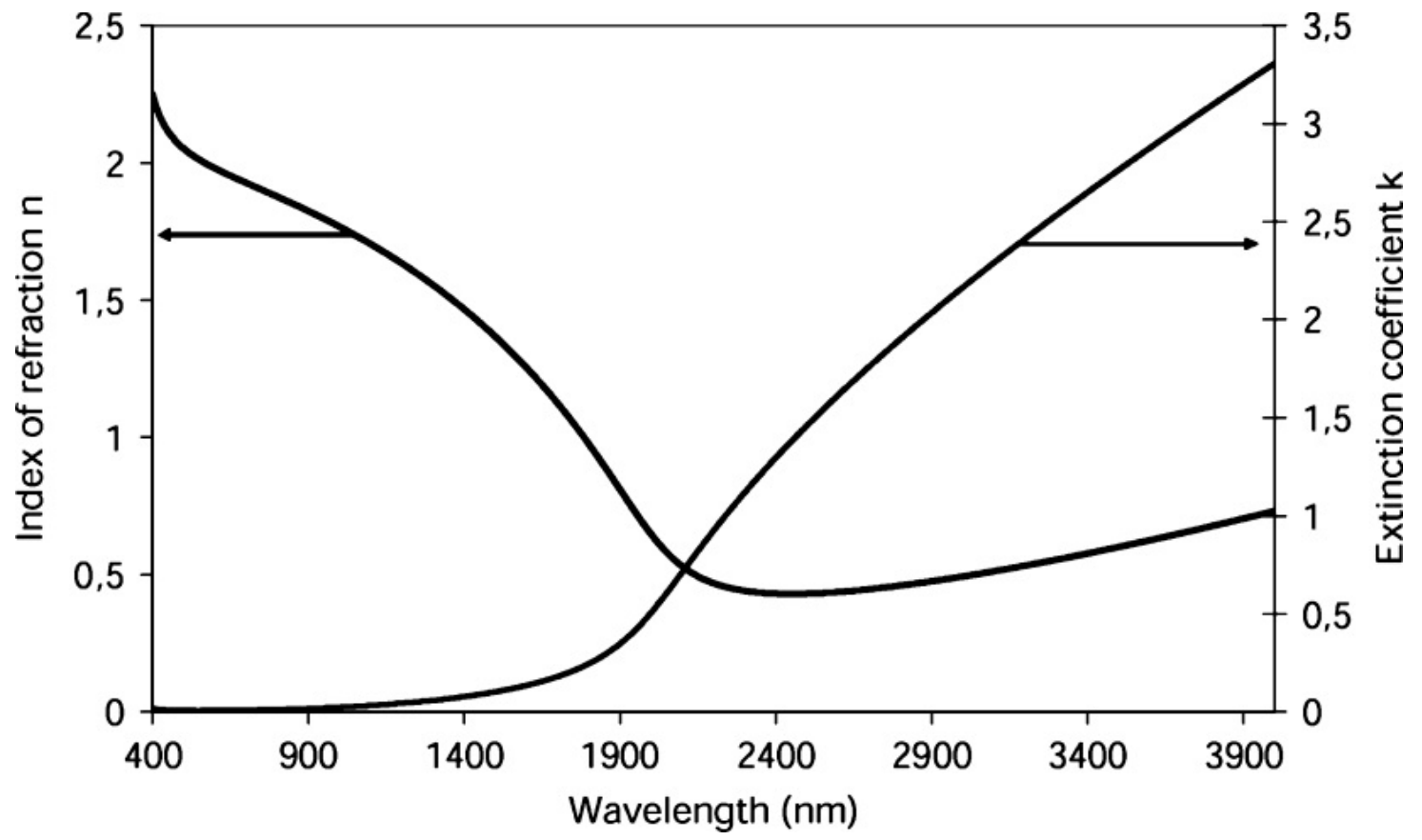

Figure 6. ITO refractive index curve. Shown are the optical properties suitable for the generation of LMR and SPR at shorter and longer wavelength ranges, respectively. Reprinted from [18] with permission from IEEE.

The deposition of ITO on flat surfaces has been reported as a successful mechanism for LMR generation. Using a Kretschmann configuration [17], ITO thin film proved to be able to generate resonance in both TE and TM polarizations, obtaining sensitivities of 700 and $1200 \mathrm{~nm} / \mathrm{RIU}$, respectively, while a SPR is simultaneously observed with a sensitivity of $8300 \mathrm{~nm} / \mathrm{RIU}$ for an SRI of 1.47. Recently, microscope coverslips coated with an ITO layer have been used as planar waveguides in a fiber setup to induce LMR [25], obtaining high sensitivity values (1405 and $920 \mathrm{~nm} / \mathrm{RIU}$ for TE and TM modes, respectively). A similar setup using either a microscope glass slide or a coverslip coated with ITO and located in a poly(methyl methacrylate) (PMMA) block was used for the fabrication of a relative humidity sensor based on LMR [26].

One of the applications of ITO coatings for the fabrication of LMR-based sensors is the measuring of relative humidity (RH). In [19], a segment of cladding-removed 200/225 $\mu \mathrm{m}$ core/cladding MMF coated with ITO was used for the fabrication of a RH sensor with a sensitivity of $0.283 \mathrm{~nm} / \% \mathrm{RH}$. This research also showed how the fabrication of an overlay of a material highly sensitive to humidity as PAH-PAA over the ITO coating improved the sensitivity to $0.833 \mathrm{~nm} / \% \mathrm{RH}$. The same fiber configuration was also used for the fabrication of a turbine oil degradation sensor in [27]. Here, the reported device was capable of measuring the degradation of oil by measuring the LMR shift induced by the variation on the RI as a function of the oil degradation, obtaining a sensitivity of $0.15 \times 10^{-3} \mathrm{~nm} / \mathrm{h}$ (each hour of degradation induced a $0.15 \times 10^{-3} \mathrm{~nm}$ shift in average).

ITO-coated MMF has also been used for other interesting applications, such as the detection of hydrogen $\left(\mathrm{H}_{2}\right)$ [7]. This work compares the performance of three $\mathrm{H}_{2}$ sensors using a LMR support coating that consisted of an ITO thin film, ITO nanoparticles (NPs), and a layer of ITO NPs over an ITO thin film. These devices obtained sensitivity values of $0.32,0.58$, and $0.71 \mathrm{~nm} / \mathrm{ppm}$, respectively, proving that the use of ITO NPs enhances the sensitivity of the layer in the presence of $\mathrm{H}_{2}$.

Some novel setups have been designed for the improvement of the sensitivity of LMR-based sensors. In particular, in [14] the fabrication of an ITO coating on a tapered MMF end was proposed to observe LMR in a reflection setup. This configuration achieved a theoretical sensitivity of $12,005 \mathrm{~nm} / \mathrm{RIU}$, which is 1.4 times higher than the value simulated for a straight fiber. 
As mentioned before, one of the most relevant differences in practice in LMR compared to SPR is the fact that LMR can be observed in both TE and TM modes, making it easier to observe them without the use of polarized light. However, as the LMR can be generated at different wavelengths for each mode (TE and TM), the isolation of modes facilitates the possibility to obtain narrower resonances with higher sensitivity. This allows a better figure of merit (FOM) to be obtained, defined as the sensitivity/FWHM (full width at half maximum) ratio, as the ratio increases for more sensitive and narrower resonances. For this purpose, D-shaped fibers have been used for the fabrication of LMR-based sensors (Figure 7). In particular, a refractometer based on a D-shaped fiber narrowed the width of a LMR to $5.3 \mathrm{~nm}$ and reported a sensitivity of $8742 \mathrm{~nm} / \mathrm{RIU}$ in the range of 1.36-1.38 RI [28]. A more recent work [16] reported a sensitivity of 136,276 nm/RIU in the range of 1.447-1.449 RI, with a peak of $304,361 \mathrm{~nm} / \mathrm{RIU}$. Here, it is important to consider the measuring SRI range, because a characteristic behavior of LMR is that the sensitivity increases at high RI ranges, which is confirmed by these results.

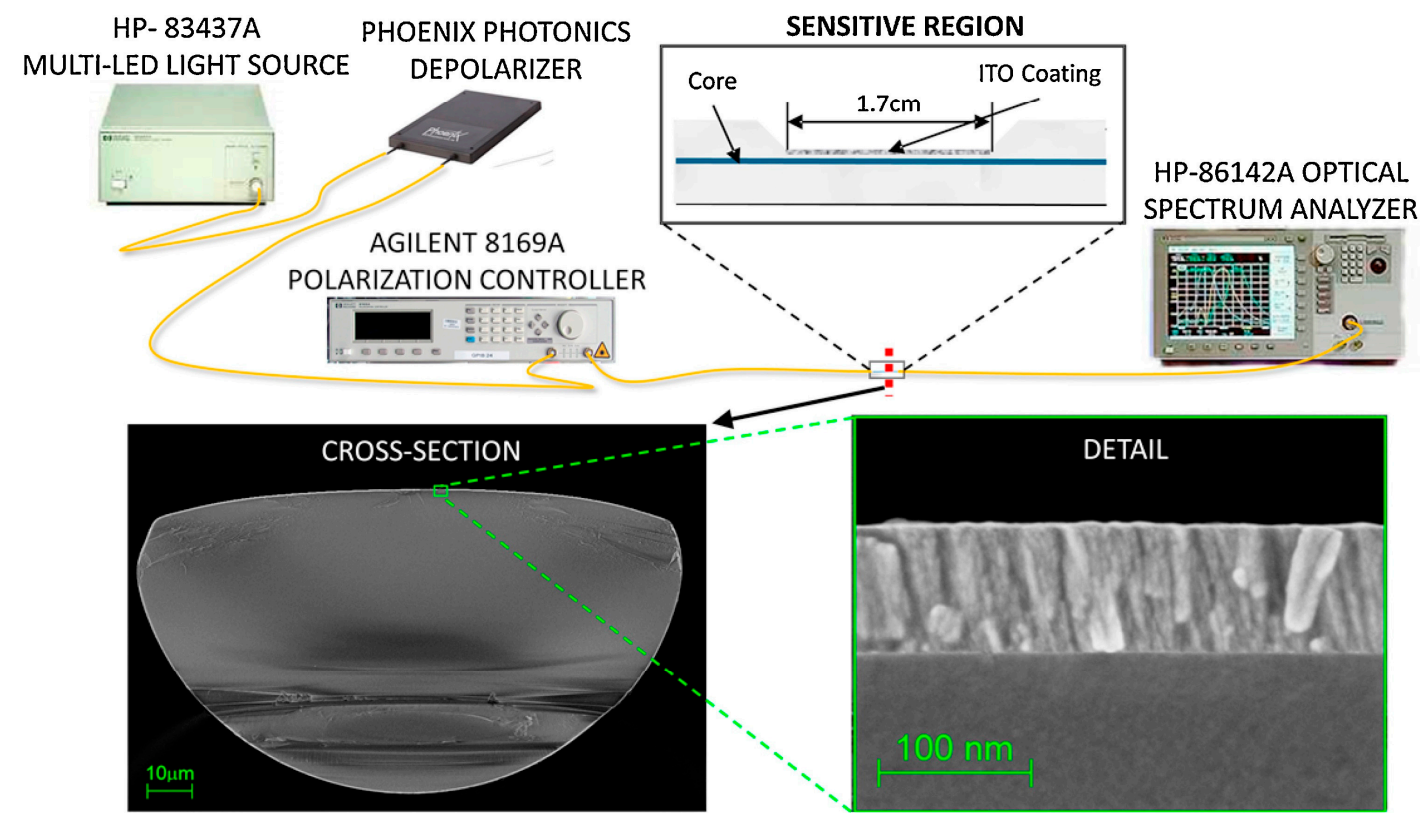

Figure 7. Example of LMR-based refractometer using a D-shaped fiber. A 17-mm long segment of side-polished single-mode fiber (SMF) was coated with an ITO thin film. The geometry of this structure can be appreciated in the cross-section image obtained by SEM. Reprinted from [16] with permission from Elsevier.

Several biosensors based on ITO thin films have also been reported in the literature. A C-reactive protein (CRP) sensor was designed using a combination of ITO and poly(allylamine hydrochloride-poly(sodium 4-styrenesulfonate) (PAH-PSS) coatings on a D-shaped fiber [21]. This device showed a sensitivity of up to $169.93 \mathrm{~nm} / \mathrm{mg} \mathrm{L}^{-1}$ and achieved a limit of detection (LOD) of $0.0625 \mathrm{mg} / \mathrm{L}$. Another example is an immunoglobulin G sensor fabricated on an ITO-coated MMF, which was functionalized by adding a poly(methyl methacrylate) layer and immobilized antibodies, achieving a LOD of $3.5 \mu \mathrm{g} / \mathrm{L}$ [29].

From another perspective, some authors have taken advantage of the electrical conductivity of ITO for the development of LMR-based electrochemical sensors using ITO-coated MMFs [20,24,30,31]. For instance, an optical ketoprofen sensor was reported by Smietana et al. in [20]. This device monitored the electropolymerization of ketoprofen on an ITO coating showing, a LOD of $0.536 \mathrm{mM}$.

As a summary, the most relevant studies reported using ITO coatings for the fabrication of LMR-based sensors are shown in Table 1. 


\subsection{Tin Oxide}

Another widely used material for the fabrication of LMR refractometers is tin oxide. It presents a number of similarities in comparison with ITO, since tin oxide is one of the components of ITO. Optically, $\mathrm{SnO}_{2}$ presents a slightly higher refractive index, which according to theory, permits higher sensitivities to SRI to be obtained [6]. This idea has been experimentally proven in several works using D-shaped fibers coated with a $\mathrm{SnO}_{2}$ thin film. In particular, a sensor working in the 1.321-1.326 RI (refractive index) range obtained a sensitivity of 14,501 nm/RIU [16], while a later work experimenting in the 1.441-1.449 RI range (Figure 8) reported a maximum sensitivity of $1,087,889 \mathrm{~nm} / \mathrm{RIU}$ [32]. Such results imply that the refractive index could be measured with a resolution of $9.19 \times 10^{-10}$ using an OSA with a standard resolution of 1 picometer.
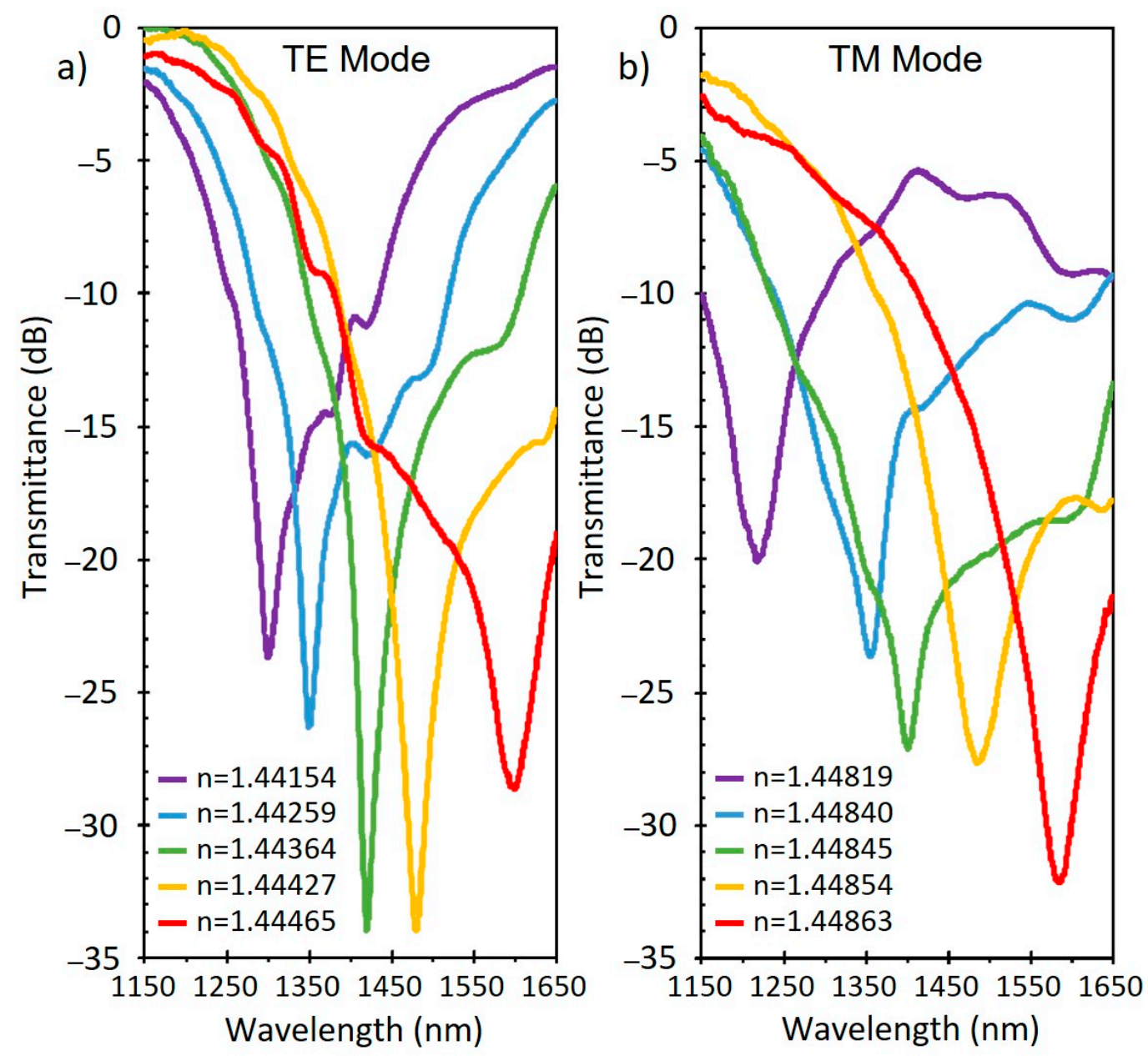

Figure 8. Transmittance of a D-shaped fiber with a tin oxide thin film with different SRI. Shown is the LMR corresponding to the TE mode (a) and TM mode (b). Reprinted from [32].

A tin oxide thin-film-based LMR refractometer was also used to monitor turbine oil degradation [27]. In this case, the sensitivity was improved up to $0.27 \times 10^{-3} \mathrm{~nm} / \mathrm{h}$ (each hour of degradation induced a $0.27 \times 10^{-3} \mathrm{~nm}$ shift on average. This material has also been reported for the fabrication of relative humidity sensors. In this sense, an etched SMF coated with a $\mathrm{SnO}_{2}$ thin film of $140 \mathrm{~nm}$ demonstrated a sensitivity of $1.9 \mathrm{~nm} / \% \mathrm{RH}$ [33].

In the field of biosensing, $\mathrm{SnO}_{2}$ has also been frequently studied. An immunoglobulin $\mathrm{G}$ (IgG) sensor using tin oxide over two different fiber structures was reported in [29]. Here, a configuration based on a $200 \mu \mathrm{m}$ core MMF was capable to achieve a LOD of $0.9 \mu \mathrm{g} / \mathrm{L}$, while the setup based on a D-shaped fiber reached a LOD of $0.15 \mu \mathrm{g} / \mathrm{L}$, which are both comparatively better than the results 
obtained using an ITO coating. This improvement is a direct consequence of the higher sensitivity of tin oxide coating based refractometers. Additionally, a D-dimer sensor was studied in [34] using a tin-oxide-coated D-shaped fiber. This work presents LODs of $10 \mathrm{ng} / \mathrm{mL}$ and $100 \mathrm{ng} / \mathrm{mL}$ when tested in buffer and human serum, respectively, with response times of 10-20 min, which fit the range of other D-dimer detection platforms.

Most of the analyzed studies report $\mathrm{SnO}_{2}$ coatings fabricated by means of sputtering. However, there are other methods available for this purpose. Layer-by-layer (LbL) has also been proven as a valid option for the fabrication of $\mathrm{SnO}_{2}$ coatings. In [35], a $600 \mu \mathrm{m}$ core MMF coated with $\mathrm{SnO}_{2}-\mathrm{PSS}$ bilayers was used in the design of a fiber refractometer in the range of 1.33-1.38 RI. This device reached a sensitivity of $4080 \mathrm{~nm} / \mathrm{RIU}$, but this value was increased up to $4704 \mathrm{~nm} / \mathrm{RIU}$ when a SnO${ }_{2}$ NP (nanoparticles) layer was added to the previous film.

Other dip coating techniques have also been described for the fabrication of LMR-based sensors using $\mathrm{SnO}_{2}$ nanoparticles. In [36], four possible combinations of a dual coating were tested for the development of an arsenite sensor. The two possibilities for the first layer were a tin oxide thin film or a $\mathrm{SnO}_{2} \mathrm{NP}$ coating. Then, two different options were used for the second layer: one was a $\alpha-\mathrm{Fe}_{2} \mathrm{O}_{3}$ $\mathrm{NP}$ layer, and the second was a core-shell nanostructure comprising $\alpha-\mathrm{Fe}_{2} \mathrm{O}_{3} \mathrm{NP}$ core with a $\mathrm{SnO}_{2}$ shell, abbreviated as $\alpha$-Fe@Sn core-shell (CS). The combination of $\mathrm{SnO}_{2}$ NPs and $\alpha$-Fe@Sn CS, which achieved the highest performance, allowed the generation of LMR at a wavelength of $370 \mathrm{~nm}$. This device presented a sensitivity of $1.31 \mathrm{~nm} / \mu \mathrm{g} \mathrm{L}{ }^{-1}$, with a LOD of $0.99 \mu \mathrm{g} / \mathrm{L}$.

The above are not the only cases where two different layers were combined to improve the characteristics of the sensors. The use of a graphene oxide (GO) overlayer onto a 220-nm thick $\mathrm{SnO}_{2}$ thin film that proved to improve the sensitivity to ethanol by $210 \%$ is also described in [37].

As explained previously, one of the multiple reported configurations consisted of a planar waveguide (coverslip) where light was coupled from and to a MMF [25]. In this case, the coverslip was coated with $\mathrm{SnO}_{2}$, obtaining sensitivities of 800 and $1510 \mathrm{~nm} / \mathrm{RIU}$ for the TE and TM modes, respectively. Another promising structure consisting of a multimode-coreless-multimode (MCM) fiber was also recently reported in [38]. In this configuration, where a $20 \mathrm{~mm}$ segment of $\mathrm{SnO}_{2}$-coated coreless fiber is fused to a couple of MMF pigtails, the proposed device reached a sensitivity of 7,346 nm/RIU when characterized as a refractometer. Additionally, the device was also used for the fabrication of a IgG detector, obtaining a LOD of $0.6 \mathrm{mg} / \mathrm{L}$. A comparison of the performance of all the discussed sensors is shown in Table 1 at the end of the document.

\subsection{Indium Oxide}

The other component of ITO, indium oxide $\left(\operatorname{In}_{2} \mathrm{O}_{3}\right)$, has not received as much attention as ITO or tin oxide in the LMR field. Most of the reported devices are associated with humidity or refractive index sensors (see Table 1). An early work demonstrated the fabrication of $\operatorname{In}_{2} \mathrm{O}_{3}$ coatings on a 200- $\mu \mathrm{m}$ core diameter CRMOF using the dip coating method [39]. In this case, three refractometers with increasing $\mathrm{In}_{2} \mathrm{O}_{3}$ film thickness were manufactured. All three devices presented 2 resonances, corresponding to the TE and TM modes, which could be observed separately at certain wavelengths. As the film thickness increased, the spectral positions of these resonances shifted to a longer wavelength. The sensor with the thickest coating $(86 \mathrm{~nm})$ presented resonances in the longest wavelengths (950 and 1400), which caused these resonances to have the highest sensibility (4255 and $4926 \mathrm{~nm} / \mathrm{RIU}$ ). This behavior is explained [6] by the fact that the LMR located at longer wavelengths show greater sensitivity than when they are observed at shorter wavelengths, due to having a thinner coating. This extensive work also demonstrated the response of this device to several VOCs (volatile organic compounds such as isopropyl alcohol, ethanol, methanol, and acetone), along with the cross-sensitivity to RH (Figure 9) and temperature. Figure 9 also shows the fast dynamical response of these sensors, which was faster than the $1 \mathrm{~min}$ resolution of the test. 

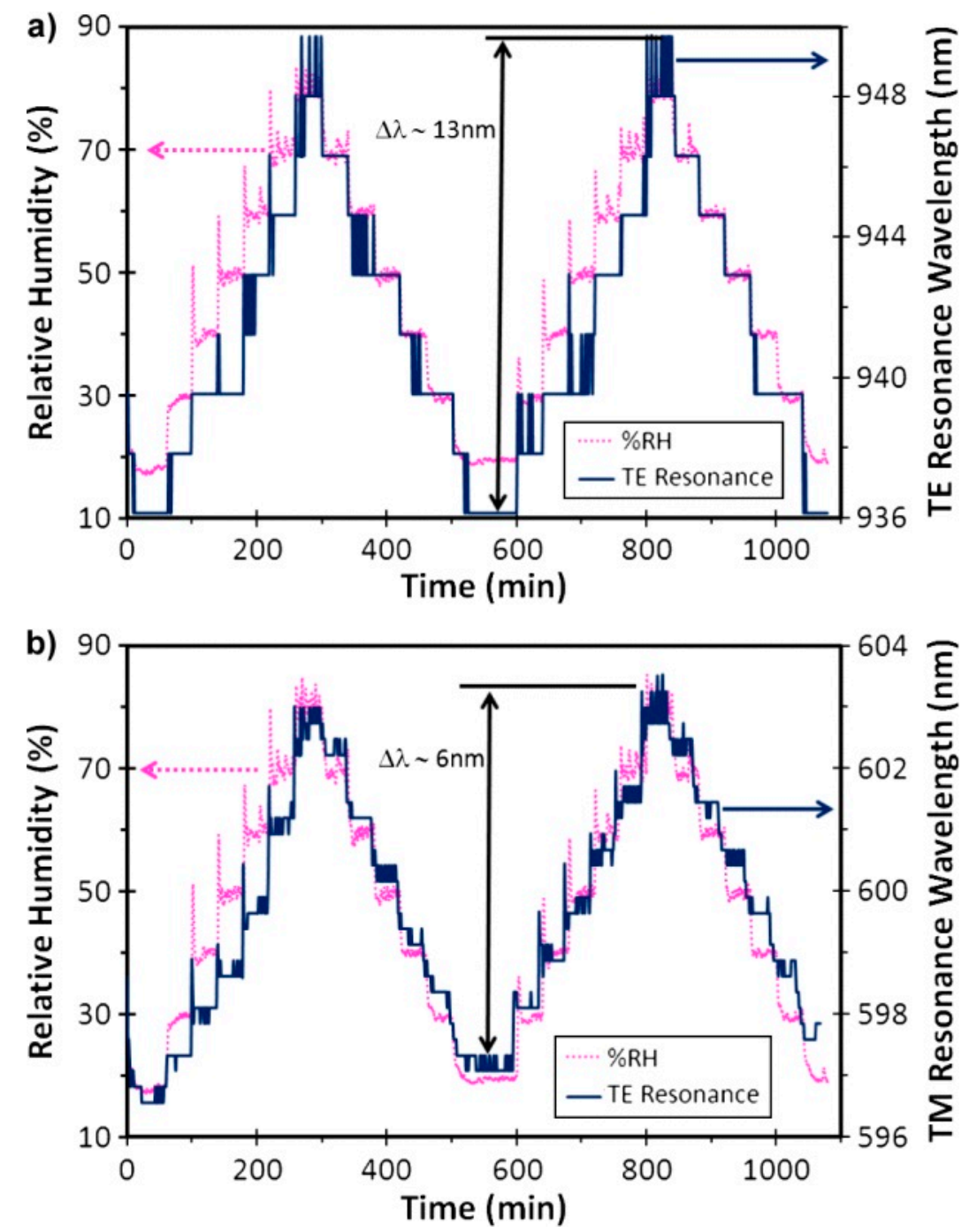

Figure 9. Relative humidity sensitivity test preformed for a $\operatorname{In}_{2} \mathrm{O}_{3}$-based sensor. The curve obtained from the LMR probe closely follows the one provided by the electronic RH sensor in both TE (a) and TM (b) modes. Reprinted from [39] with permission from IEEE.

A research work where ITO thin films were fabricated using the dip coating technique for the development of $\mathrm{RH}$ sensors also described the utilization of $\mathrm{In}_{2} \mathrm{O}_{3}$ for the same purpose [19]. In this case, an $85 \mathrm{~nm}$ layer of $\mathrm{In}_{2} \mathrm{O}_{3}$ was deposited onto a $200 \mu \mathrm{m}$ CRMOF, resulting in two dips corresponding to the LMR caused by the two propagation modes, as explained above. A second device was designed by depositing a $115 \mathrm{~nm}$ layer of ITO via a similar procedure. These probes were later coated by PAH-PAA coatings by means of LbL to observe the effects of such overlays on the response of RH. Prior to the deposition of the polymeric coatings, the sensitivity to SRI variations was tested, showing that $\mathrm{In}_{2} \mathrm{O}_{3}$ reached higher values (4000 and $3333 \mathrm{~nm} / \mathrm{RIU}$ for TE and TM modes, respectively) than ITO $(1520 \mathrm{~nm} / \mathrm{RIU})$. In contrast, when the response to relative humidity was studied, it was seen that the resonance values generated by $\operatorname{In}_{2} \mathrm{O}_{3}(0.133$ and $0.042 \mathrm{~nm} / \% \mathrm{RH})$ showed lower sensitivity than the ITO probe $(0.283 \mathrm{~nm} / \% \mathrm{RH})$. This difference in the sensitivity response to SRI and $\mathrm{RH}$ is explained by the more porous nature of the ITO coating, which permits greater penetration and interaction with water molecules, inducing a greater LMR wavelength shift. However, when the RH-sensitive PAH-PAA coating was added, the response of the $\operatorname{In}_{2} \mathrm{O}_{3}$ sensor was better. In particular, the resonance located at a longer wavelength (corresponding to the TE mode) in the case of $\operatorname{In}_{2} \mathrm{O}_{3}$ reached a sensitivity of 
$0.935 \mathrm{~nm} / \% \mathrm{RH}$, whereas the device based on the ITO and PAH-PAA layers obtained a sensitivity of $0.833 \mathrm{~nm} / \%$ RH.

Recently, a new approach was taken regarding indium oxide coatings for LMR generation. In this case, the $\mathrm{In}_{2} \mathrm{O}_{3}$ films were fabricated by a sputtering system onto microscope glass slides and coverslips [40]. These devices acted as planar waveguides when light was launched laterally from an optical fiber on one side and collected back on the opposite side. The $\operatorname{In}_{2} \mathrm{O}_{3}$ film on the slides allowed the generation of LMR and the introduction of a light polarizer before the slide permitted the easy separation of propagation modes. A first probe was fabricated with a 276-nm thick $\operatorname{In}_{2} \mathrm{O}_{3}$ coating, which allowed the observation of a second-order LMR. This device obtained a sensitivity of $162 \mathrm{~nm} / \mathrm{RIU}$ in the RI range of 1.33-1.357, which increased to $1375 \mathrm{~nm} / \mathrm{RIU}$ when the RI range increased to 1.492-1.508. A second device was fabricated with a thinner coating $(74 \mathrm{~nm})$ in order to observe the first order resonance, which should be more sensitive. In this case, the sensitivity in the range of $1.33-1.357$ reached a value of $929 \mathrm{~nm} / \mathrm{RIU}$, which is almost 6 times higher than the sensitivity obtained for the same RI range with the second-order LMR.

The discussed results obtained with $\operatorname{In}_{2} \mathrm{O}_{3}$-based coatings are summarized in Table 1 at the end of the text for a better comparison.

\subsection{Zinc Oxide}

The next relevant group of metal oxides used for the generation of LMR consists of those based on zinc oxide. This material also fulfills the optical requirements for the generation of LMR and can be fabricated by common methods such as sputtering or thermal evaporation. However, the first experimental demonstrations of LMR-based optical fiber refractometers using zinc oxide were reported only a few years ago [11,41]. These works relied on the capability of zinc oxide to react with hydrogen sulfide $\left(\mathrm{H}_{2} \mathrm{~S}\right)$ gas for the design and fabrication of LMR-based hydrogen sulfide sensors. Different structures involving $\mathrm{ZnO}$ nanoparticles (NP) and $\mathrm{ZnO}$ nanorods (NR) were analyzed in these works in order to maximize the sensitivity of the LMR-based devices to $\mathrm{H}_{2} \mathrm{~S}$ gas. A sensitivity of $1.06 \mathrm{~nm} / \mathrm{ppm}$ was obtained when a $\mathrm{ZnO}$ NP layer was deposited directly on the fiber, which was increased up to $1.49 \mathrm{~nm} / \mathrm{ppm}$ when a $12 \mathrm{~nm}$ thin film of $\mathrm{ZnO}$ was fabricated onto the fiber before the deposition of the NPs [41]. These figures were well above the results obtained when the same fiber structure was coated with silver thin film and an overlayer of zinc oxide to fabricate a SPR-based sensor, which could only achieve a sensitivity of $0.24 \mathrm{~nm} / \mathrm{ppm}$. Later, this mechanism was further enhanced by integrating $\mathrm{ZnO}$ nanorods, with a sensitivity enhancement of up to $4.14 \mathrm{~nm} / \mathrm{ppm}$ [11]. A later work analyzed and compared the performance of these types of LMR-generating coatings as refractometers [8]. In this way, $400 \mu \mathrm{m}$ core CRMOFs were coated with either a $\mathrm{ZnO}$ thin film, a $\mathrm{ZnO}$ thin film followed by a $\mathrm{ZnO} \mathrm{NP}$ coating, or a $\mathrm{ZnO}$ thin film followed by a $\mathrm{ZnO}$ NR layer. All three structures were fabricated in a way that they presented LMR in a close wavelength (between 350 and $390 \mathrm{~nm}$ ), so that their performance could be compared more directly. This study showed that a single zinc oxide thin film could provide a sensitivity of $760 \mathrm{~nm} / \mathrm{RIU}$, which could be increased to $950 \mathrm{~nm} / \mathrm{RIU}$ by adding a layer of ZnO NPs and could be further improved using a layer of $\mathrm{ZnO}$ nanorods ( $1160 \mathrm{~nm} / \mathrm{RIU}$ ).

Aiming to improve the performance of LMR-based refractometers, $\mathrm{ZnO}$ thin film was also used in a novel structure [42]. This structure consisted of a CRMOF with a $400 \mu \mathrm{m}$ core diameter, which was bent in order to achieve a U-shaped fiber, using a dual sensing approach to enhance the accuracy of the refractometer, measuring the LMR shift and the absorbance variation simultaneously. Additionally, this paper also introduces a novel approach to the use of LMR-based sensors, determining the SRI function of the variation of FWHM of the LMR instead of the wavelength shift. It is claimed that the use of FWHM provides 4 times higher sensitivity than the measured wavelength shift $(895 \mathrm{~nm} / \mathrm{RIU}$ compared to $220 \mathrm{~nm} / \mathrm{RIU}$, respectively).

Although zinc oxide coatings have not been as extensively reported for the fabrication of LMR-based sensors as the previous cases, they have already been considered for the development of LMR-based biosensors. A cortisol sensor using $\mathrm{ZnO}$ thin film and a molecularly imprinted polymer 
layer (MIP) was developed on a MMF [43]. In this work, it was demonstrated that a variation of the concentration of cortisol could induce a shift above $51 \mathrm{~nm}$ in a LMR, providing a sensitivity of up to $12.86 \mathrm{~nm} / \log (\mathrm{g} / \mathrm{mL})$ and a LOD of $25.9 \mathrm{fg} / \mathrm{mL}$. The tests demonstrated the durability and stability of the device, which also showed a response time of $20 \mathrm{~s}$. Similarly, a urinary p-cresol sensor was developed, which also relied on the MIP mechanism [44]. In this case, a zinc oxide and molybdenum sulfide $\left(\mathrm{MoS}_{2}\right)$ nanocomposite was used for the fabrication of a LMR support coating. $\mathrm{MoS}_{2}$ was included in the nanocomposite for the purpose of altering the refractive index of the coating, improving the sensitivity of the device. In this way, the proposed sensor achieved a sensitivity of $11.86 \mathrm{~nm} / \mu \mathrm{M}$, with a LOD of $28 \mathrm{nM}$.

Zinc oxide thin film has also been considered for the development of LMR-based pressure sensors [45]. This theoretical work proposed the fabrication of a hafnium dioxide $\left(\mathrm{HfO}_{2}\right)$ overlay on top of the zinc oxide thin film in order to maximize the sensitivity. With this structure, a sensitivity of $837 \mathrm{~nm} / \mathrm{MPa}$ (and a maximum of $2000 \mathrm{~nm} / \mathrm{MPa}$ ) was calculated when a LMR-based refractometer was inserted in a rubber block, whose refractive index was dependent on the applied pressure. A summary of the LMR-based devices using $\mathrm{ZnO}$ thin films can be found in Table 1.

It is interesting to note that some coatings based on doped zinc oxide have also been studied for the development of LMR-based sensors. An aluminum-doped zinc oxide (AZO) thin film was proposed for the fabrication of LMR-based refractometers on a MMF tip. Theoretical simulations reported a sensitivity of $3500 \mathrm{~nm} / \mathrm{RIU}$, increasing to $8500 \mathrm{~nm} / \mathrm{RIU}$ with the utilization of a dual coating $\left(\mathrm{AZO}-\mathrm{TiO}_{2}\right)$ [15]. Later, an experimental work showed the feasibility of the utilization of AZO for the generation of LMR-based refractometers by means of a $167 \mathrm{~nm}$ thin film [46]. This work showed the simultaneous generation of 3 LMR in the VIS-NIR range (visible and near-infrared spectrum), with a maximum sensitivity of $1153.6 \mathrm{~nm} / \mathrm{RIU}$ for the lower-order resonance.

Recently, AZO coatings have been used in single-multimode-single mode (SMS) fiber setups [47]. First, the performance of two different multimode fibers was studied. A CRMOF (which had been etched for cladding removal) was used to fabricate a device that achieved a sensitivity of $937.8 \mathrm{~nm} / \mathrm{RIU}$. Substituting this fiber with a no-core fiber (NCF), the sensitivity increased to $1002.1 \mathrm{~nm} / \mathrm{RIU}$. This improvement was attributed to the larger diameter of the NCF (125 $\mu \mathrm{m}$ vs. $105 \mu \mathrm{m}$ in the CRMOF), which also led to wider resonance. After optimizing the structure, the study compared the results when an AZO with a higher aluminum content was used for the fabrication of the coating. For this purpose, two targets with different Al concentrations (98:2 and 92:8) were used in the RF sputtering deposition process. It was shown that a higher aluminum content induced an improvement in the sensitivity of the refractometer, which reached $1214.7 \mathrm{~nm} / \mathrm{RIU}$.

Another well-known variant of zinc oxide, indium-gallium-doped zinc oxide (IGZO) has also been studied as a LMR support material [48]. IGZO coatings were fabricated on a $200 \mu \mathrm{m}$ core diameter MMF and a series of D-shaped fibers with the purpose of fabricating LMR-based refractometers. On MMF, a LMR was observed at a wavelength of $640 \mathrm{~nm}$. This device showed a sensitivity of $1666 \mathrm{~nm} / \mathrm{RIU}$ when the fiber was immersed in solutions of RI varying between 1.33 and 1.45. Later, a series of D-shaped fibers was coated with IGZO to obtain LMR in the wavelength range between 1150 and $1650 \mathrm{~nm}$. This configuration increased the sensitivity up to $12,929 \mathrm{~nm} / \mathrm{RIU}$. This paper also researched the impact of the polishing depth in the D-shaped fibers on the LMR, concluding that a deeper polishing depth induces a greater amplitude in the LMR and may alter its shape (generating "side-lobes"), but does not have a significant impact on the sensitivity of the LMR to SRI.

\subsection{Titanium Dioxide}

It was mentioned in the previous section that a structure consisting of a $\mathrm{TiO}_{2}$ film over an $\mathrm{AZO}$ layer was considered for the design of LMR-based refractometers. Titanium dioxide itself is also considered a very promising material for the development of optical LMR sensors, since it possesses a high refractive index and because $\mathrm{TiO}_{2}$-based coatings can be fabricated in a number of ways, such as by sputtering or layer-by-layer. An early work presented a TiO2/PSS thin film fabricated by LbL 
technique onto a $200 \mu \mathrm{m}$ core diameter CRMOF. This device enables the generation of a LMR at a wavelength of $1100 \mathrm{~nm}$, achieving a sensitivity of $2872 \mathrm{~nm} / \mathrm{RIU}$ [49]. A recent work using a similar coating on a $600 \mu \mathrm{m}$ core CRMOF obtained a sensitivity of $6754 \mathrm{~nm} / \mathrm{RIU}$ at a wavelength of $650 \mathrm{~nm}$ [50]. In this case, a reflection setup was used for the characterization of the device, which also presented thinner coatings than the previous case $(126 \mu \mathrm{m}$ instead of $460 \mu \mathrm{m})$. These conditions permitted the observation of lower-order LMR, which show greater sensitivity. Another work presented the use of the reactive sputtering technique for the fabrication of $\mathrm{TiO}_{2}$ thin film on a D-shaped fiber [51]. This $84 \mathrm{~nm}$ film generated a resonance at a wavelength of $1300 \mathrm{~nm}$, but showed a sensitivity lower than the previous case of only $4122 \mathrm{~nm} / \mathrm{RIU}$. Following the experiences described with the previous materials, the use of a D-shaped fiber should not decrease the sensitivity of the sensor. The fact that a different deposition technique and different reagents are used in this research implies that the optical properties of the fabricated film may be quite different, which could have caused this unexpected result.

Another experimental use of $\mathrm{TiO}_{2}$ for the fabrication of optical LMR sensors was reported, seeking to design an ammonia sensor [52]. This work reports a $\mathrm{TiO}_{2}$ based coating deposited onto a tapered SMF by liquid phase deposition (LPD) process. This coating contains porphyrin, which is capable of interacting with ammonia as a functional material. This coating induces a LMR at $850 \mathrm{~nm}$, which shifts in the presence of ammonia, obtaining a LOD of $0.116 \mathrm{ppm}$.

It should be noted that $\mathrm{TiO}_{2}$ thin films have also been used for the theoretical study of new fiber structures to fabricate LMR-based refractometers. The use of $\mathrm{TiO}_{2}$ coatings on a grapefruit PCF (photonic crystal fiber) with an exposed core has been recently reported [53]. This study suggests that appropriate waveguide selection could improve the sensitivity of LMR-based refractometers to $68,000 \mathrm{~nm} / \mathrm{RIU}$ using a 100-nm thick $\mathrm{TiO}_{2}$ film. It also suggests the fabrication of a $\mathrm{HfO}_{2}$ layer on top of the $\mathrm{TiO}_{2}$ film, since the appropriate combination of thickness $(80 / 20 \mathrm{~nm})$ enhanced the sensitivity to $84,000 \mathrm{~nm} / \mathrm{RIU}$, with a maximum peak of $140,000 \mathrm{~nm} / \mathrm{RIU}$. A similar work proposed the addition of a rubber layer on top of the $\mathrm{TiO}_{2} / \mathrm{HfO}_{2}$ coating with a varying $\mathrm{RI}$ in the pressure application function (Figure 10) [54]. This would allow the fabrication of a pressure sensor that could achieve a sensitivity of $5 \mu \mathrm{m} / \mathrm{MPa}$, according to the simulations.

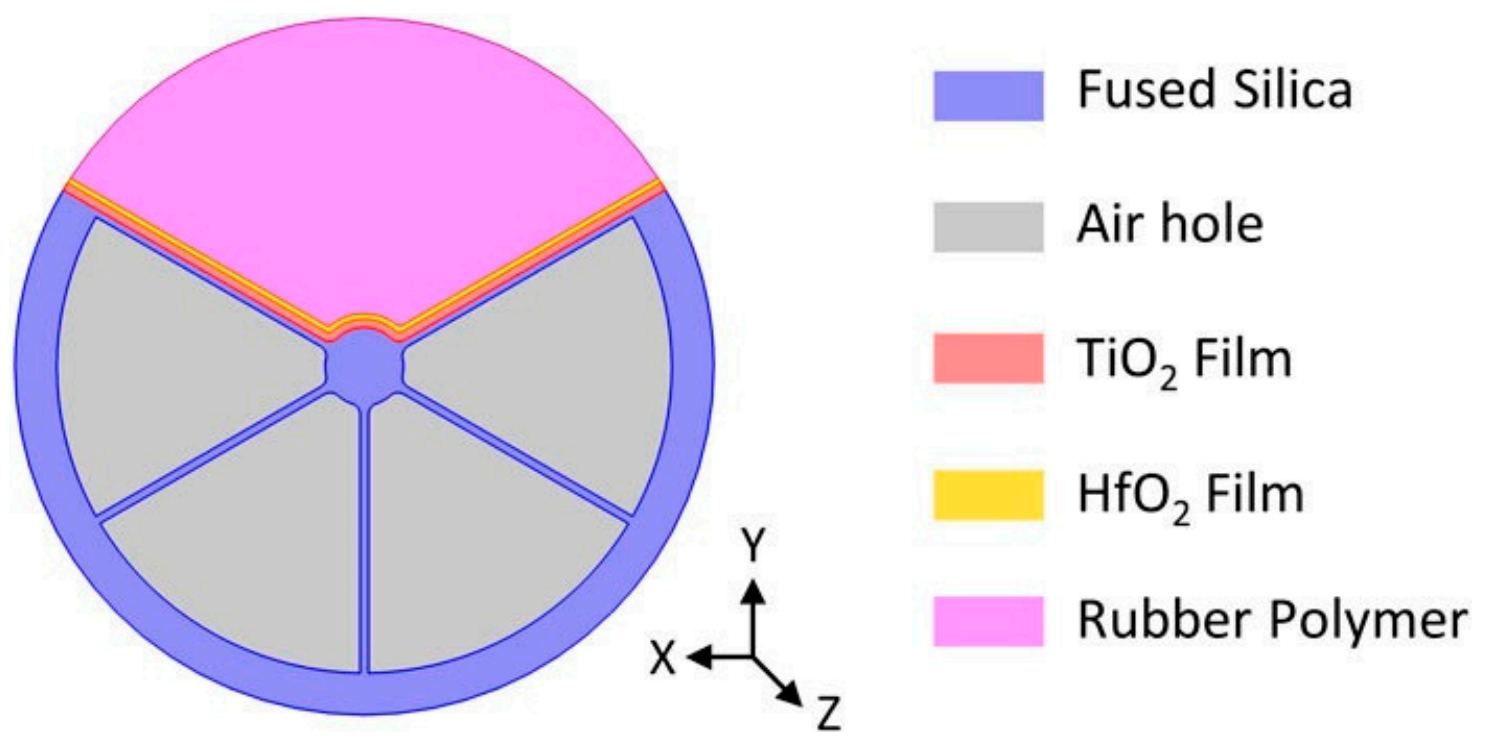

Figure 10. Cross-section of the grapefruit PCF structure proposed for the fabrication of a LMR-based pressure sensor. Reprinted from [54].

Table 1 at the end of the text presents a brief summary of the devices presented in this section. 


\subsection{Polymers}

Previous sections have dealt with coatings based on metal oxides for the generation of lossy mode resonance. It should be noted that some of the discussed coatings also included polymeric layers in their composition, which are mainly associated with sensing applications. In fact, LMR generation is not restricted to the use of metal oxides. Polymeric films are also capable of supporting LMR generation on their own, as long as their optical properties match the required conditions. For instance, a LMR-based sensor using polymeric coatings was reported for the sensing of $\mathrm{pH}$ [55]. A coating consisting of PAH-PAA bilayers deposited by LbL was chosen due to the swelling-deswelling behavior it presents with variation in $\mathrm{pH}$. This change in the thickness of the coatings induces a wavelength shift in the LMR, and thus acts like a $\mathrm{pH}$ monitor. Figure 11 shows the transmission spectra on the fiber as PAH-PAA bilayers are added. It can be seen how several LMR are generated as the coating thickens, with each resonance showing a different slope. It is worth noting that the first LMR has the greatest slope, and the following ones present lower values. This slope indicates the sensitivity of the LMR to the thickness variation, is related to the sensitivity to SRI, and agrees with the premise that the lower order LMR are more sensitive. Following this procedure, two different probes were fabricated with 100 and 25 polymeric bilayers, respectively, in order to generate a LMR of second and first orders in the 500-700 nm range. These devices showed sensitivity values to $\mathrm{pH}$ 3-6 of 25 and $36.67 \mathrm{~nm} / \mathrm{pH}$, respectively.

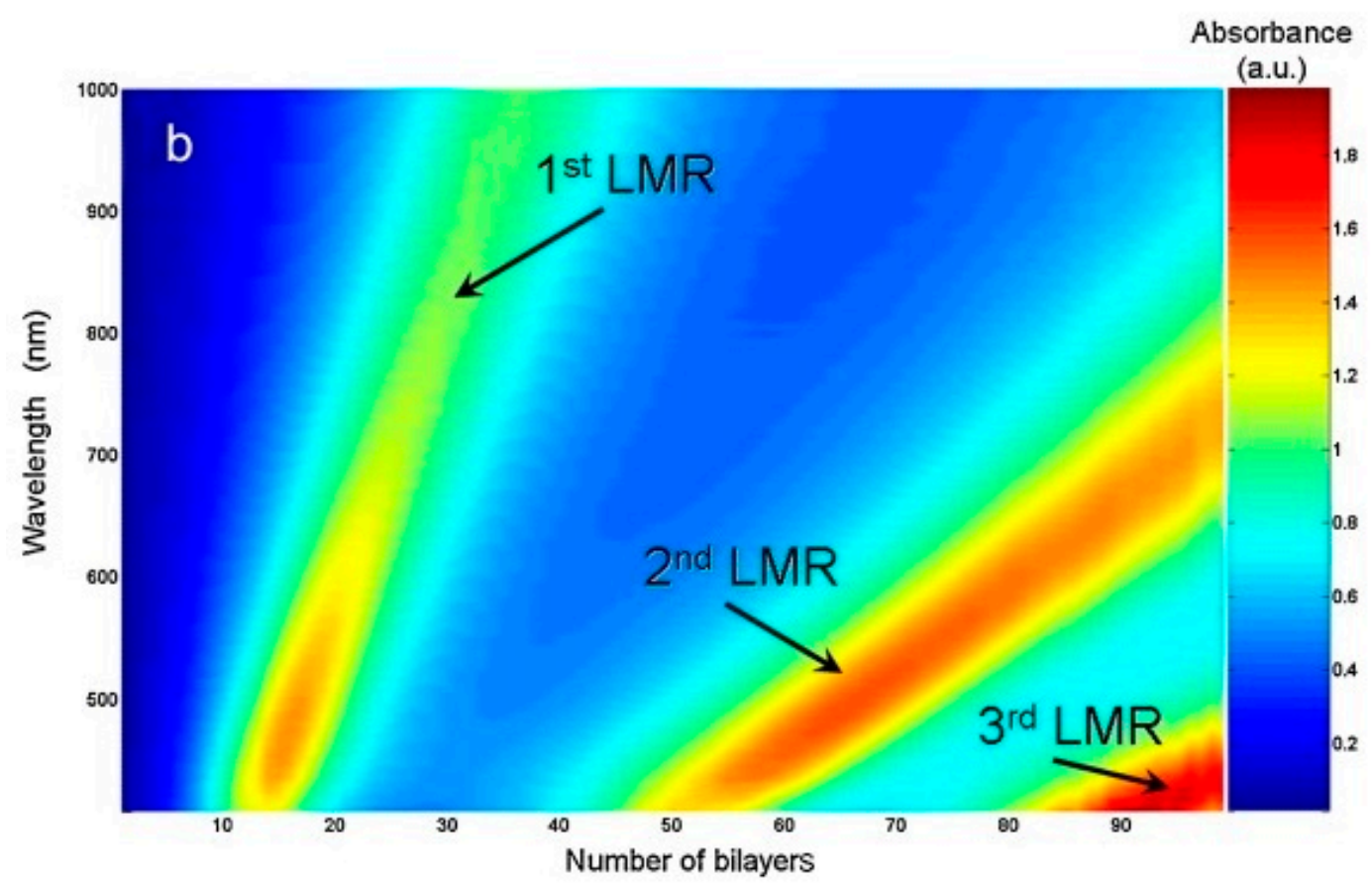

Figure 11. Transmittance spectra of a $200 \mu \mathrm{m}$ CRMOF as polyallylamine hydrochloride (PAH) and polyacrylic acid (PAA) bilayers are being deposited on it. Several absorption bands can be observed, corresponding to LMR. Reprinted from [55] with permission from Elsevier.

A different kind of polymeric coating was also studied for the development of $\mathrm{pH}$ optical sensors, including gold nanoparticles in the polymeric matrix [56]. A PAH-PAA-Au NP coating deposited by layer-by-layer method on a CRMOF induced LMR at $750 \mathrm{~nm}$ and localized surface plasmon resonance (LSPR) at $530 \mathrm{~nm}$. This probe was submerged in buffer solutions with $\mathrm{pH}$ values ranging between 4.0 and 6.0, showing a wavelength shift of both resonances as a function of the $\mathrm{pH}$ of the solutions. In particular, LSPR and LMR showed sensitivity values of $0.75 \mathrm{~nm} / \mathrm{pH}$ and $67.35 \mathrm{~nm} / \mathrm{pH}$, respectively.

For the same purpose, D-shaped fibers were also coated with PAH-PAA bilayers. In this case, the $\mathrm{pH}$ of the solutions involved in the LbL fabrication process was adjusted in order to obtain two probes 
working in two different $\mathrm{pH}$ ranges [12]. The first probe was designed to operate in a $\mathrm{pH}$ range of 7-8, while the second probe was conceived for operation in the $\mathrm{pH}$ range of 4-5. In the first probe, the LMR corresponding to the TM and TE reached sensitivities of 30 and $34 \mathrm{~nm} / \mathrm{pH}$, respectively. In the second probe, the two resonances obtained sensitivities of 61 and $69 \mathrm{~nm} / \mathrm{pH}$, respectively.

Polymeric coatings were also used for the measurement of other parameters, such as relative humidity [9]. As mentioned previously, PAH-PAA layers present a high sensitivity to relative humidity. The indicated work studied several probes coated with PAH-PAA bilayers characterizing LMR of first and second orders at different wavelengths. The device with the best performance obtained a sensitivity of $0.51 \mathrm{~nm} / \% \mathrm{RH}$. This value fell behind the previously reported sensitivity of $0.935 \mathrm{~nm} / \% \mathrm{RH}$ when the probe contained a $\mathrm{In}_{2} \mathrm{O}_{3}$ thin film beneath the PAH-PAA coating [19]. These results demonstrate the importance of using a LMR support coating that presents a high sensitivity, in this case in combination with a polymeric coating that reacts with the measured parameter.

Nanoparticles were also included in the polymeric coating matrices for the fabrication of relative humidity sensors. A PAH-PAA-Ag NP coating, for instance, was fabricated on a $200 \mu \mathrm{m}$ core CRMOF in order to simultaneously induce a LMR and a LSPR, thanks to the addition of silver NPs [57]. In this device, the LMR achieved a sensitivity to RH of $0.943 \mathrm{~nm} / \% \mathrm{RH}$, while the LSPR remained almost invariant $(0.06 \mathrm{~nm} / \% \mathrm{RH})$. A similar behavior was reported in another work, where dual LSPR and LMR phenomena were observed due to the presence of gold nanorods (GNR) [58]. A LbL coating of gold nanorods embedded in PSS (PAH/GNR@PSS) was capable of generating LSPR in two bands (LSPR-T at $530 \mathrm{~nm}$ and LSPR-L at $720 \mathrm{~nm}$, related to the transverse and longitudinal plasmons, respectively) and LMR at $850 \mathrm{~nm}$. As in the previous case, the LSPR were not very sensitive to RH variations (below $0.13 \mathrm{~nm} / \% \mathrm{RH})$. In contrast, LMR achieved a sensitivity value of $11.2 \mathrm{~nm} / \% \mathrm{RH}$.

Table 1 presents a brief summary of these sensors.

Table 1. Performance of the different sensors based on the LMR detailed in this paper. A wide range of applications has been developed based on this phenomenon using a variety of materials. The sensors are sorted by coating material, configuration setup, and application.

\begin{tabular}{|c|c|c|c|c|c|}
\hline Material & Configuration & $\begin{array}{c}\text { Refractive } \\
\text { Index Range }\end{array}$ & Wavelength & Application/Sensitivity & Ref. \\
\hline ITO + PAH-PAA & $200 \mu \mathrm{m}$ MMF & N/A & 1430 & $\begin{array}{l}\text { Relative Humidity: } \\
0.833 \mathrm{~nm} / \% \mathrm{RH}\end{array}$ & [19] \\
\hline ITO & $200 \mu \mathrm{m}$ MMF & N/A & 750 & $\begin{array}{l}\text { Turbine oil degradation: } \\
0.15 \times 10^{-3} \mathrm{~nm} / \mathrm{h}\end{array}$ & [27] \\
\hline ITO & $200 \mu \mathrm{m}$ MMF & N/A & 550 & $\begin{array}{c}\text { Immunoglobulin G LOD: } \\
3.5 \mu \mathrm{g} / \mathrm{L}\end{array}$ & [29] \\
\hline ITO & $400 \mu \mathrm{m} \mathrm{MMF}$ & N/A & 600 & $\begin{array}{l}\text { Ketoprofen: } 1400.86 \mathrm{~nm} / \mathrm{M} \\
\text { LOD: } 0.536 \mathrm{mM}\end{array}$ & [20] \\
\hline ITO + ITO NPs & $600 \mu \mathrm{m}$ MMF & N/A & 400 & $\mathrm{H}_{2}$ Gas: $0.71 \mathrm{~nm} / \mathrm{ppm}$ & [7] \\
\hline ITO & D-shaped & $1.365-1.38$ & 1250 & $\begin{array}{l}\text { Refractive Index: } \\
8742 \mathrm{~nm} / \mathrm{RIU}\end{array}$ & [28] \\
\hline ITO & Coverslip & $1.33-1.37$ & 800 & $\begin{array}{l}\text { Refractive Index: } \\
1405 \mathrm{~nm} / \mathrm{RIU}\end{array}$ & [25] \\
\hline ITO & Coverslip & N/A & 570 & $\begin{array}{l}\text { Relative Humidity: } \\
0.116 \mathrm{~nm} / \% \mathrm{RH}\end{array}$ & [26] \\
\hline $\mathrm{SnO}_{2}$ & $200 \mu \mathrm{m}$ MMF & $\mathrm{N} / \mathrm{A}$ & 1100 & $\begin{array}{l}\text { Turbine oil degradation: } \\
0.27 \times 10^{-3} \mathrm{~nm} / \mathrm{h}\end{array}$ & [27] \\
\hline $\mathrm{SnO}_{2}+\mathrm{GO}$ & $200 \mu \mathrm{m}$ MMF & N/A & 537 & $\begin{array}{l}\text { Ethanol: } 0.525 \\
\text { nm/\%Eth(v/v) }\end{array}$ & [37] \\
\hline
\end{tabular}


Table 1. Cont.

\begin{tabular}{|c|c|c|c|c|c|}
\hline Material & Configuration & $\begin{array}{l}\text { Refractive } \\
\text { Index Range }\end{array}$ & Wavelength & Application/Sensitivity & Ref. \\
\hline $\mathrm{SnO}_{2}-\mathrm{PSS}+\mathrm{SnO}_{2} \mathrm{NPs}$ & $600 \mu \mathrm{m}$ MMF & $1.33-1.38$ & 840 & $\begin{array}{l}\text { Refractive Index: } \\
4704 \mathrm{~nm} / \mathrm{RIU}\end{array}$ & [35] \\
\hline $\mathrm{SnO}_{2}$ & Etched SMF & N/A & 1550 & $\begin{array}{c}\text { Relative Humidity: } \\
1.9 \mathrm{~nm} / \% \mathrm{RH}\end{array}$ & [33] \\
\hline $\mathrm{SnO}_{2} \mathrm{NPs}+\alpha-\mathrm{Fe} @ \mathrm{Sn} \mathrm{CS}$ & Unclad Fiber & N/A & 370 & $\begin{array}{l}\text { Arsenite: } 1.31 \mathrm{~nm} / \mu \mathrm{g} \mathrm{L}^{-1} \\
\text { LOD: } 0.99 \mu \mathrm{g} / \mathrm{L}\end{array}$ & [36] \\
\hline $\mathrm{SnO}_{2}$ & D-shaped & $1.321-1.326$ & 1380 & $\begin{array}{c}\text { Refractive Index: } \\
14,501 \mathrm{~nm} / \mathrm{RIU}\end{array}$ & [16] \\
\hline $\mathrm{SnO}_{2}$ & D-shaped & $1.448-1.449$ & 1200 & $\begin{array}{l}\text { Refractive Index: } \\
1,087,889 \mathrm{~nm} / \mathrm{RIU}\end{array}$ & [32] \\
\hline $\mathrm{SnO}_{2}$ & D-shaped & N/A & 1445 & $\begin{array}{c}\text { Immunoglobulin G LOD: } \\
0.15 \mathrm{ng} / \mathrm{L}\end{array}$ & [29] \\
\hline $\mathrm{SnO}_{2}$ & D-shaped & N/A & 1400 & $\begin{array}{l}\text { Dimer-D LOD: } 10 \text { and } \\
100 \mathrm{ng} / \mathrm{mL} \text { in buffer and } \\
\text { human serum resp. }\end{array}$ & [34] \\
\hline $\mathrm{SnO}_{2}$ & $\mathrm{MCM}$ & N/A & 750 & $\begin{array}{c}\text { Immunoglobulin G LOD: } \\
0.6 \mathrm{mg} / \mathrm{L}\end{array}$ & [38] \\
\hline $\mathrm{SnO}_{2}$ & Coverslip & $1.33-1.37$ & 900 & $\begin{array}{l}\text { Refractive Index: } \\
1800 \mathrm{~nm} / \mathrm{RIU}\end{array}$ & [25] \\
\hline $\mathrm{In}_{2} \mathrm{O}_{3}$ & $200 \mu \mathrm{m}$ MMF & $1.32-1.37$ & 1400 & $\begin{array}{l}\text { Refractive Index: } \\
4926 \mathrm{~nm} / \mathrm{RIU}\end{array}$ & [39] \\
\hline $\mathrm{In}_{2} \mathrm{O}_{3}+\mathrm{PAH}-\mathrm{PAA}$ & $200 \mu \mathrm{m}$ MMF & N/A & 1020 & $\begin{array}{l}\text { Relative Humidity: } \\
0.935 \mathrm{~nm} / \% \mathrm{RH}\end{array}$ & [19] \\
\hline $\mathrm{In}_{2} \mathrm{O}_{3}$ & Coverslip & $1.333-1.357$ & 730 & $\begin{array}{l}\text { Refractive Index: } \\
929 \mathrm{~nm} / \mathrm{RIU}\end{array}$ & [40] \\
\hline $\mathrm{ZnO}$ & $\begin{array}{c}400 \mu \mathrm{m} \text { U-shaped } \\
\text { MMF }\end{array}$ & $1.33-1.42$ & 400 & $\begin{array}{l}\text { Refractive Index: } \\
220 \mathrm{~nm} / \mathrm{RIU}\end{array}$ & [42] \\
\hline $\mathrm{ZnO}+\mathrm{ZnO} \mathrm{NRs}$ & $400 \mu \mathrm{m}$ MMF & $1.33-1.44$ & 390 & $\begin{array}{l}\text { Refractive Index: } \\
1160 \mathrm{~nm} / \mathrm{RIU}\end{array}$ & [8] \\
\hline $\mathrm{ZnO}-\mathrm{MoS}_{2}$ & $600 \mu \mathrm{m}$ MMF & N/A & 380 & $\begin{array}{c}\text { Urinary p-cresol: } \\
11.86 \mathrm{~nm} / \mu \mathrm{M} \text { LOD: } 28 \mathrm{nM}\end{array}$ & [44] \\
\hline $\mathrm{ZnO}+\mathrm{ZnO}-\mathrm{PPY}$ & $600 \mu \mathrm{m}$ MMF & N/A & 400 & $\begin{array}{l}\text { Cortisol: } 12.86 \mathrm{~nm} / \mathrm{log} \\
\text { (g/mL) LOD: } 25.9 \mathrm{fg} / \mathrm{mL}\end{array}$ & [43] \\
\hline $\mathrm{ZnO}+\mathrm{ZnO}$ nanorods & $600 \mu \mathrm{m}$ MMF & N/A & 350 & Sulfide gas: $4.14 \mathrm{~nm} / \mathrm{ppm}$ & [11] \\
\hline $\mathrm{ZnO}+\mathrm{ZnO} \mathrm{NPs}$ & $600 \mu \mathrm{m}$ MMF & N/A & 370 & Sulfide gas:1.49 nm/ppm & [41] \\
\hline AZO & $200 \mu \mathrm{m}$ MMF & $1.3334-1.4471$ & 1200 & $\begin{array}{l}\text { Refractive Index: } \\
1153.6 \mathrm{~nm} / \mathrm{RIU}\end{array}$ & [46] \\
\hline AZO & SMS & $1.365-1.405$ & 1530 & $\begin{array}{l}\text { Refractive Index: } \\
1214.7 \mathrm{~nm} / \mathrm{RIU}\end{array}$ & [47] \\
\hline IGZO & D-shaped & $1.39-1.42$ & 1150 & $\begin{array}{l}\text { Refractive Index: } \\
12,929 \mathrm{~nm} / \mathrm{RIU}\end{array}$ & [48] \\
\hline $\mathrm{TiO}_{2}-\mathrm{PSS}$ & $200 \mu \mathrm{m}$ MMF & $1.32-1.43$ & 1100 & $\begin{array}{l}\text { Refractive Index: } \\
2872.73 \mathrm{~nm} / \mathrm{RIU}\end{array}$ & [49] \\
\hline $\mathrm{TiO}_{2}-\mathrm{PSS}$ & $600 \mu \mathrm{m}$ MMF & $1.33-1.38$ & 650 & $\begin{array}{l}\text { Refractive Index: } \\
6754 \mathrm{~nm} / \mathrm{RIU}\end{array}$ & [50] \\
\hline $\mathrm{TiO}_{2}$ & D-shaped & $1.333-1.398$ & 1300 & $\begin{array}{l}\text { Refractive Index: } \\
4122 \mathrm{~nm} / \mathrm{RIU}\end{array}$ & [51] \\
\hline $\mathrm{TMPyP} \mathrm{TiO}_{2}$ & Tapered SMF & N/A & 850 & Ammonia LOD: 0.16 ppm & [52] \\
\hline PAH-PAA & $200 \mu \mathrm{m}$ MMF & N/A & 610 & $\mathrm{pH}(3-6): 36.67 \mathrm{~nm} / \mathrm{pH}$ & [55] \\
\hline PAH-PAA & D-shaped & N/A & 1397 & $\mathrm{pH}(4-5): 69 \mathrm{~nm} / \mathrm{pH}$ & [12] \\
\hline PAH-PAA-AuNP & $200 \mu \mathrm{m}$ MMF & N/A & 750 & $\mathrm{pH}(4-6): 67.35 \mathrm{~nm} / \mathrm{pH}$ & [56] \\
\hline
\end{tabular}


Table 1. Cont.

\begin{tabular}{|c|c|c|c|c|c|}
\hline Material & Configuration & $\begin{array}{l}\text { Refractive } \\
\text { Index Range }\end{array}$ & Wavelength & Application/Sensitivity & Ref. \\
\hline PAH-PAA & $200 \mu \mathrm{m}$ MMF & N/A & 700 & $\begin{array}{c}\text { Relative Humidity: } \\
0.51 \mathrm{~nm} / \% \mathrm{RH}\end{array}$ & [9] \\
\hline PAH-GNR@PSS & $200 \mu \mathrm{m}$ MMF & N/A & 850 & $\begin{array}{l}\text { Relative Humidity: } \\
11.2 \mathrm{~nm} / \% \mathrm{RH}\end{array}$ & [58] \\
\hline PAH-PAA-Ag NPs & $200 \mu \mathrm{m}$ MMF & N/A & 750 & $\begin{array}{c}\text { Relative Humidity: } \\
0.943 \mathrm{~nm} / \% \mathrm{RH}\end{array}$ & [57] \\
\hline Graphene Oxide (GO) & $200 \mu \mathrm{m}$ MMF & $1.39-1.42$ & 550 & $\begin{array}{l}\text { Refractive Index: } \\
12,460 \mathrm{~nm} / \mathrm{RIU}\end{array}$ & [59] \\
\hline $\mathrm{CuO}$ & Coverslip & $1.33-1.37$ & 750 & $\begin{array}{l}\text { Refractive Index: } \\
1537 \mathrm{~nm} / \mathrm{RIU}\end{array}$ & [25] \\
\hline $\mathrm{ZrO}_{2}$ & $400 \mu \mathrm{m}$ MMF & $1.41-1.43$ & 700 & $\begin{array}{l}\text { Refractive Index: } \\
880 \mathrm{~nm} / \mathrm{RIU}\end{array}$ & [10] \\
\hline $\mathrm{Si}_{\mathrm{x}} \mathrm{N}_{\mathrm{y}}+\mathrm{Ta}_{2} \mathrm{O}_{5}$ & $400 \mu \mathrm{m}$ MMF & $1.33-1.35$ & 770 & $\begin{array}{l}\text { Refractive Index: } \\
1077 \mathrm{~nm} / \mathrm{RIU}\end{array}$ & [10] \\
\hline
\end{tabular}

\subsection{Other Materials}

Previous sections have summarized the most widely used materials for the fabrication of LMR-based sensors. Several metal oxides and some polymers present the ideal properties in terms of electrical dispersion and thin film fabrication possibilities, making them good choices for this purpose. However, there are other materials that were not cited in the previous sections that have gained more attention for the support of LMR in recent works. For instance, graphene oxide (GO), which has already been described above because of its use as an overlay to enhance the sensitivity of a $\mathrm{SnO}_{2}$ thin film based sensor, was also experimentally tested in [59]. Two different sensors were fabricated in this work using 8 and 20 bilayers of GO and polyethylenimine (PEI) by means of the LbL technique on a $200 \mu \mathrm{m}$ core CRMOF. The number of bilayers was chosen to obtain LMR of different orders but at the same wavelength $(550 \mathrm{~nm})$ in both probes. The probes were later tested on solutions of increasing refractive indices, obtaining sensitivity values of 2631 and 12,460 nm/RIU for the devices with 20 and 8 bilayers, respectively.

Another interesting material that has been recently considered for the fabrication of LMR refractometers is copper oxide [25]. The high refractive index of this material reveals a great potential for the development of highly sensitive refractometers that are comparable to tin oxide.

A recent work [10] presented a number of coating materials that can be deposited by atomic layer deposition (ALD) and demonstrated their capability to fabricate LMR-based sensors. This deposition technique is chosen because of its capacity to control the growth rate with great precision, which is a key aspect for the fabrication of LMR-based sensors. ALD was used to fabricate hafnium oxide $\left(\mathrm{HfO}_{2}\right)$ and zirconium oxide $\left(\mathrm{ZrO}_{2}\right)$ thin films on a $400 \mu \mathrm{m}$ core CRMOF. Figure 12 shows the transmission spectra for such devices when immersed on solutions of increasing SRI. Thin films of silicon nitride $\left(\mathrm{Si}_{\mathrm{x}} \mathrm{N}_{\mathrm{y}}\right)$ were also fabricated by plasma-enhanced chemical vapor deposition (PECVP). This technique is not as precise as ALD, but in contrast it allows the fabrication of thicker coatings in a reasonable time. A fourth kind of probe consisted of the fabrication of a tantalum oxide $\left(\mathrm{Ta}_{2} \mathrm{O}_{5}\right)$ film on top of the silicon nitride layer by ALD. This structure is designed so that a thick coating can be fabricated in a reasonable timeframe $\left(\mathrm{Si}_{\mathrm{x}} \mathrm{N}_{\mathrm{y}}\right.$ by PECVD), while at the same time allowing fine-tuning with the addition of the $\mathrm{Ta}_{2} \mathrm{O}_{5}$ overlay with ALD. The $\mathrm{ZrO}_{2}$ probe obtained sensitivity values of 195 and $880 \mathrm{~nm} / \mathrm{RIU}$ for the RI ranges of 1.33-1.45 and 1.41-1.43, respectively. In the case of the silicon-nitride-based sensor, it obtained sensitivity values of 289.5 and $593.5 \mathrm{~nm} / \mathrm{RIU}$ for the same RI ranges. When the tantalum oxide film was deposited on the silicon nitride layer, the sensitivity of the device for the lower RI range increased to $1077 \mathrm{~nm} / \mathrm{RIU}$, but the opposite behavior was obtained for the 1.43-1.45 range as the sensitivity slightly decreased to $483 \mathrm{~nm} /$ RIU. Table 1 summarizes these results. 


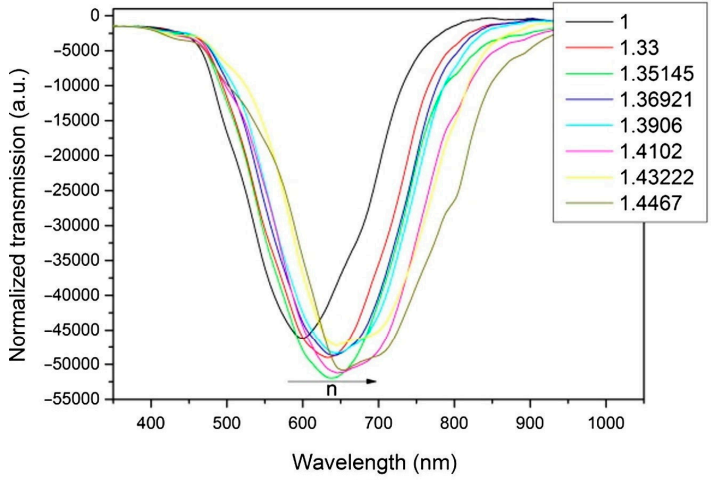

(a)

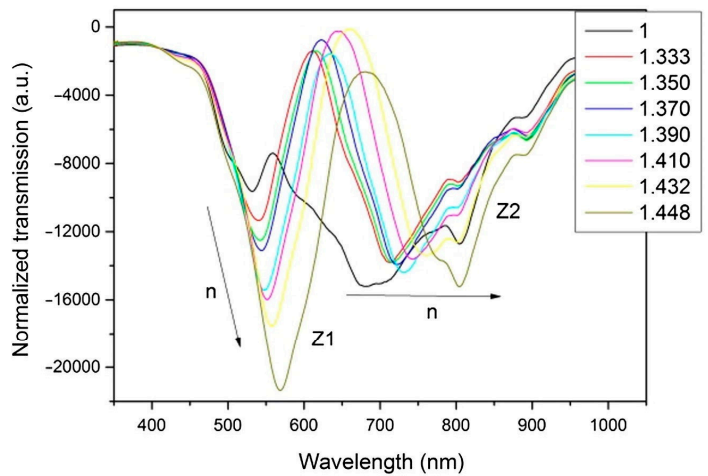

(b)

Figure 12. Transmission spectra of $\mathrm{HfO}_{2}$ (a) and a $\mathrm{ZrO}_{2}$ (b)-coated CRMOF for different SRI. Reprinted from [10] with permission from Elsevier.

\section{Conclusions}

A number of materials have already been studied for the generation of LMR-based sensors. Each coating material has led to the development of LMR-based sensors for different purposes with diverse results. The increasing number of studies in this field during the last decade highlights the versatility of LMR for the development of sensors. In this sense, materials such as ITO, tin oxide, indium oxide, PAH, PAA, and even silver nanoparticles or gold nanorods have been used for the fabrication of relative humidity sensors $[9,19,33,57,58]$.

Nanoparticles (NPs) have been widely used in layers for the fabrication of gas sensors, as this structure increases the interaction surface. For example, it was already mentioned that a combination of layers of $\mathrm{SnO}_{2} \mathrm{NPs}$ and $\alpha$-Fe@SnO CS facilitated the fabrication of an arsenite sensor [36]. It was also described how the addition of NPs to an ITO layer increased the performance of a hydrogen sensor [7]. The fabrication of a second layer of ZnO NPs and NRs on top of a zinc oxide thin film also increased the sensitivity of a hydrogen sulfide sensor [11,41].

Zinc oxide thin films have also been used in the fabrication of LMR-based sensors using molecularly imprinted polymers (MIPs) [43,44].

It should be noted that the described sensors have been fabricated using different deposition techniques. Those relying on dip coating or layer-by-layer techniques (such as the polymeric coatings) can be implemented faster than those relying on techniques such as sputtering deposition or ALD, for instance, which require a more economically demanding infrastructure.

The sensitivity of the lossy mode resonance to external refractive index variations has been extensively studied, especially in the range close to water (1.33), since most biological applications work in this range. For instance, a graphene oxide coating [59] provided a sensitivity of $2631 \mathrm{~nm} / \mathrm{RIU}$ at a wavelength of $550 \mathrm{~nm}$, while a $\mathrm{TiO}_{2} / \mathrm{PSS}$ film [50] produced LMR with a sensitivity of $6754 \mathrm{~nm} / \mathrm{RIU}$ at $650 \mathrm{~nm}$. Additionally, a $\mathrm{In}_{2} \mathrm{O}_{3}$-based refractometer [39] gave a value of $3003 \mathrm{~nm} / \mathrm{RIU}$ at $600 \mathrm{~nm}$, which increased to $4926 \mathrm{~nm} / \mathrm{RIU}$ when a thicker coating shifted the LMR to $1400 \mathrm{~nm}$; all of these examples used CRMOF. Using a D-shaped fiber setup, a refractometer based on an ITO thin film [28] gave a sensitivity of $8742 \mathrm{~nm} / \mathrm{RIU}$. That figure was almost doubled (14,501 nm/RIU) when a coating of tin oxide was used instead [16].

In terms of sensitivity, the highest figures were achieved with $\mathrm{SnO}_{2}$ coatings in both the refractive index range of water [16] and in the range of fused silica [32]. These results were due to the optical properties of the thin film, which were in agreement with the established theory that predicts that a LMR support coating with a high refractive index will lead to devices with high sensitivity to SRI variations [6]. Accordingly, several biosensors have been designed using tin oxide coatings as LMR support coatings, aiming to obtain the lowest possible limit of detection (LOD), as is the case D-dimer [34] and immunoglobulin G [29] sensors. 
However, tin oxide optical properties are not as exceptional. In fact, there are other materials whose refractive indices do not differ much from that of $\mathrm{SnO}_{2}$ that are potentially capable of generating LMR with as good or even higher sensitivity. Materials such a copper oxide, which possesses a higher refractive index and a low extinction coefficient, could surpass the performance of tin oxide in the fabrication of lossy mode resonance based sensors. However, a potentially high sensitivity is not the only parameter to consider when it comes to finding the best material for the fabrication of sensors. Other considerations such as the porosity of the films, stability, fabrication process, and affinity with the functionalizing layer must be taken into consideration for the selection of the LMR support material. The possibility of designing a structure of two (or more) layers $[10,37]$ is a promising approach for the optimization of these sensors. The phenomenon of LMR for the fabrication of optical sensors has already proved to have great potential, and the vast number of possible materials that can be used to design such sensors represents a limitless field of research. The future research on coating materials for LMR-based refractometers should probably be focused on finding materials with an optimal refractive index to maximize sensitivity, as well as on the study of more advanced structures, such as multiple layers.

Author Contributions: All authors contributed to the preparation, writing and reviewing of the manuscript. All authors have read and agreed to the published version of the manuscript.

Funding: This research was funded by the Spanish Agencia Estatal de Investigación (AEI) and Fondo Europeo de Desarrollo Regional (FEDER) (TEC2016-78047-R), the Public University of Navarra (PJUPNA26), and the Spanish Ministry of Universities (FPU15/05663).

Conflicts of Interest: The authors declare no conflict of interest. The funders had no role in the design of the study; in the collection, analyses, or interpretation of data; in the writing of the manuscript, or in the decision to publish the results.

\section{References}

1. Lazcka, O.; Del Campo, F.J.; Muñoz, F.X. Pathogen detection: A perspective of traditional methods and biosensors. Biosens. Bioelectron. 2007, 22, 1205-1217. [CrossRef] [PubMed]

2. Fine, G.F.; Cavanagh, L.M.; Afonja, A.; Binions, R. Metal Oxide Semi-Conductor Gas Sensors in Environmental Monitoring. Sensors 2010, 10, 5469-5502. [CrossRef] [PubMed]

3. Luppa, P.B.; Sokoll, L.J.; Chan, D.W. Immunosensors-Principles and applications to clinical chemistry. Clin. Chim. Acta 2001, 314, 1-26. [CrossRef]

4. Mukhopadhyay, S.C. Wearable sensors for human activity monitoring: A review. IEEE Sens. J. 2015, 15, 1321-1330. [CrossRef]

5. Homola, J. (Ed.) Surface Plasmon Resonance Based Sensors; Springer: Berlin/Heidelberg, Germany, 2006; Volume 4, ISBN 978-3-540-33918-2.

6. Del Villar, I.; Hernaez, M.; Zamarreño, C.R.; Sánchez, P.; Fernández-Valdivielso, C.; Arregui, F.J.; Matias, I.R. Design rules for lossy mode resonance based sensors. Appl. Opt. 2012, 51, 4298. [CrossRef]

7. Mishra, S.K.; Usha, S.P.; Gupta, B.D. A lossy mode resonance-based fiber optic hydrogen gas sensor for room temperature using coatings of ITO thin film and nanoparticles. Meas. Sci. Technol. 2016, 27. [CrossRef]

8. Usha, S.P.; Gupta, B.D. Performance analysis of zinc oxide-implemented lossy mode resonance-based optical fiber refractive index sensor utilizing thin film/nanostructure. Appl. Opt. 2017, 56, 5716. [CrossRef]

9. Sanchez, P.; Zamarreno, C.R.; Hernaez, M.; Del Villar, I.; Matias, I.R.; Arregui, F.J. Considerations for Lossy-Mode Resonance-Based Optical Fiber Sensor. IEEE Sens. J. 2013, 13, 1167-1171. [CrossRef]

10. Kosiel, K.; Koba, M.; Masiewicz, M.; Śmietana, M. Tailoring properties of lossy-mode resonance optical fiber sensors with atomic layer deposition technique. Opt. Laser Technol. 2018, 102, 213-221. [CrossRef]

11. Usha, S.P.; Mishra, S.K.; Gupta, B.D. Zinc oxide thin film/nanorods based lossy mode resonance hydrogen sulphide gas sensor. Mater. Res. Express 2015, 2. [CrossRef]

12. Zubiate, P.; Zamarreño, C.R.; Del Villar, I.; Matias, I.R.; Arregui, F. Tunable optical fiber $\mathrm{pH}$ sensors based on TE and TM Lossy Mode Resonances (LMRs). Sens. Actuators B Chem. 2016, 231, 484-490. [CrossRef] 
13. Del Villar, I.; Arregui, F.J.; Zamarreño, C.R.; Corres, J.M.; Bariain, C.; Goicoechea, J.; Elosua, C.; Hernaez, M.; Rivero, P.J.; Socorro, A.B.; et al. Optical Sensors Based on Lossy-Mode Resonances; Elsevier B.V.: Amsterdam, The Netherlands, 2017; Volume 240, pp. 174-185.

14. Vikas; Verma, R.K. Sensitivity enhancement of a lossy mode resonance based tapered fiber optic sensor with an optimum taper profile. J. Phys. D. Appl. Phys. 2018, 51, 415302. [CrossRef]

15. Paliwal, N.; John, J. Theoretical modeling and investigations of AZO coated LMR based fiber optic tapered tip sensor utilizing an additional $\mathrm{TiO}_{2}$ layer for sensitivity enhancement. Sens. Actuators B Chem. 2017, 238, 1-8. [CrossRef]

16. Arregui, F.J.; Del Villar, I.; Zamarreño, C.R.; Zubiate, P.; Matias, I.R. Giant sensitivity of optical fiber sensors by means of lossy mode resonance. Sens. Actuators B Chem. 2016, 232, 660-665. [CrossRef]

17. Torres, V.; Beruete, M.; Sánchez, P.; Del Villar, I. Indium tin oxide refractometer in the visible and near infrared via lossy mode and surface plasmon resonances with Kretschmann configuration. Appl. Phys. Lett. 2016, 108, 043507. [CrossRef]

18. Del Villar, I.; Zamarreño, C.R.; Hernaez, M.; Arregui, F.J.; Matias, I.R. Generation of Lossy Mode Resonances with Absorbing Thin-Films. J. Lightwave Technol. 2010, 28, 3351-3357. [CrossRef]

19. Sanchez, P.; Zamarreño, C.R.; Hernaez, M.; Del Villar, I.; Fernandez-Valdivielso, C.; Matias, I.R.; Arregui, F.J. Lossy mode resonances toward the fabrication of optical fiber humidity sensors. Meas. Sci. Technol. 2012, 23, 014002. [CrossRef]

20. Bogdanowicz, R.; Niedziałkowski, P.; Sobaszek, M.; Burnat, D.; Białobrzeska, W.; Cebula, Z.; Sezemsky, P.; Koba, M.; Stranak, V.; Ossowski, T.; et al. Optical Detection of Ketoprofen by Its Electropolymerization on an Indium Tin Oxide-Coated Optical Fiber Probe. Sensors 2018, 18, 1361. [CrossRef]

21. Zubiate, P.; Zamarreño, C.R.; Sánchez, P.; Matias, I.R.; Arregui, F.J. High sensitive and selective C-reactive protein detection by means of lossy mode resonance based optical fiber devices. Biosens. Bioelectron. 2017, 93, 176-181. [CrossRef]

22. Del Villar, I.; Torres, V.; Beruete, M. Experimental demonstration of lossy mode and surface plasmon resonance generation with Kretschmann configuration. Opt. Lett. 2015, 40, 4739. [CrossRef]

23. Del Villar, I.; Zubiate, P.; Zamarreño, C.R.; Arregui, F.J.; Matias, I.R. Optimization in nanocoated D-shaped optical fiber sensors. Opt. Express 2017, 25, 10743. [CrossRef] [PubMed]

24. Smietana, M.; Sobaszek, M.; Michalak, B.; Niedzialkowski, P.; Bialobrzeska, W.; Koba, M.; Sezemsky, P.; Stranak, V.; Karczewski, J.; Ossowski, T.; et al. Optical Monitoring of Electrochemical Processes With ITO-Based Lossy-Mode Resonance Optical Fiber Sensor Applied as an Electrode. J. Lightwave Technol. 2018, 36, 954-960. [CrossRef]

25. Fuentes, O.; Goicoechea, J.; Corres, J.M.; Del Villar, I.; Ozcariz, A.; Matias, I.R. Generation of lossy mode resonances with different nanocoatings deposited on coverslips. Opt. Express 2020, 28, 288. [CrossRef] [PubMed]

26. Fuentes, O.; Corres, J.M.; Matias, I.R.; Del Villar, I. Generation of Lossy Mode Resonances in Planar Waveguides toward Development of Humidity Sensors. J. Lightwave Technol. 2019, 37, 2300-2306. [CrossRef]

27. Sanchez, P.; Zamarreno, C.R.; Arregui, F.J.; Matias, I.R. LMR-Based Optical Fiber Refractometers for Oil Degradation Sensing Applications in Synthetic Lubricant Oils. J. Lightwave Technol. 2016, 34, 4537-4542. [CrossRef]

28. Zubiate, P.; Zamarreño, C.R.; Del Villar, I.; Matias, I.R.; Arregui, F.J.J. High sensitive refractometers based on lossy mode resonances (LMRs) supported by ITO coated D-shaped optical fibers. Opt. Express 2015, 23, 8045-8050. [CrossRef]

29. Chiavaioli, F.; Zubiate, P.; Del Villar, I.; Zamarreño, C.R.; Giannetti, A.; Tombelli, S.; Trono, C.; Arregui, F.J.; Matias, I.R.; Baldini, F. Femtomolar Detection by Nanocoated Fiber Label-Free Biosensors. ACS Sens. 2018, 3, 936-943. [CrossRef]

30. Niedziałkowski, P.; Białobrzeska, W.; Burnat, D.; Sezemsky, P.; Stranak, V.; Wulff, H.; Ossowski, T.; Bogdanowicz, R.; Koba, M.; Śmietana, M. Electrochemical performance of indium-tin-oxide-coated lossy-mode resonance optical fiber sensor. Sens. Actuators B Chem. 2019, 301, 127043. [CrossRef]

31. Sobaszek, M.; Burnat, D.; Sezemsky, P.; Stranak, V.; Bogdanowicz, R.; Koba, M.; Siuzdak, K.; Śmietana, M. Enhancing electrochemical properties of an ITO-coated lossy-mode resonance optical fiber sensor by electrodeposition of PEDOT:PSS. Opt. Mater. Express 2019, 9, 3069. [CrossRef] 
32. Ozcariz, A.; Zamarreño, C.R.; Zubiate, P.; Arregui, F.J. Is there a frontier in sensitivity with Lossy mode resonance (LMR) based refractometers? Sci. Rep. 2017, 7, 10280. [CrossRef]

33. Ascorbe, J.; Corres, J.M.; Matias, I.R.; Arregui, F. High sensitivity humidity sensor based on cladding-etched optical fiber and lossy mode resonances. Sens. Actuators B Chem. 2016, 233, 7-16. [CrossRef]

34. Zubiate, P.; Urrutia, A.; Zamarreño, C.R.; Egea-Urra, J.; Fernández-Irigoyen, J.; Giannetti, A.; Baldini, F.; Díaz, S.; Matias, I.R.; Arregui, F.J.; et al. Fiber-based early diagnosis of venous thromboembolic disease by label-free D-dimer detection. Biosens. Bioelectron. X 2019, 2, 100026. [CrossRef]

35. Wang, Q.; Li, X.; Zhao, W.-M.; Jin, S. Lossy mode resonance-based fiber optic sensor using layer-by-layer $\mathrm{SnO}_{2}$ thin film and $\mathrm{SnO}_{2}$ nanoparticles. Appl. Surf. Sci. 2019, 492, 374-381. [CrossRef]

36. Sharma, S.; Gupta, B.D. Lossy Mode Resonance-Based Fiber Optic Sensor for the Detection of As (III) Using $\alpha-\mathrm{Fe}_{2} \mathrm{O}_{3} / \mathrm{SnO}_{2}$ Core-Shell Nanostructures. IEEE Sens. J. 2018, 18, 7077-7084. [CrossRef]

37. Hernaez, M.; Mayes, A.; Melendi-Espina, S. Graphene Oxide in Lossy Mode Resonance-Based Optical Fiber Sensors for Ethanol Detection. Sensors 2017, 18, 58. [CrossRef]

38. Vicente, A.; Santano, D.; Zubiate, P.; Urrutia, A.; Del Villar, I.; Zamarreño, C.R. Lossy mode resonance sensors based on nanocoated multimode-coreless-multimode fibre. Sens. Actuators B Chem. 2020, 304, 126955. [CrossRef]

39. Zamarreno, C.R.; Sanchez, P.; Hernaez, M.; Del Villar, I.; Fernandez-Valdivielso, C.; Matias, I.R.; Arregui, F.J. Sensing Properties of Indium Oxide Coated Optical Fiber Devices Based on Lossy Mode Resonances. IEEE Sens. J. 2012, 12, 151-155. [CrossRef]

40. Fuentes, O.; Del Villar, I.; Corres, J.M.; Matias, I.R. Lossy mode resonance sensors based on lateral light incidence in nanocoated planar waveguides. Sci. Rep. 2019, 9, 8882. [CrossRef]

41. Usha, S.P.; Mishra, S.K.; Gupta, B.D. Fiber optic hydrogen sulfide gas sensors utilizing ZnO thin film/ZnO nanoparticles: A comparison of surface plasmon resonance and lossy mode resonance. Sens. Actuators $B$ Chem. 2015, 218, 196-204. [CrossRef]

42. Paliwal, N.; Punjabi, N.; John, J.; Mukherji, S. Design and Fabrication of Lossy Mode Resonance Based U-Shaped Fiber Optic Refractometer Utilizing Dual Sensing Phenomenon. J. Lightwave Technol. 2016, 34, 4187-4194. [CrossRef]

43. Usha, S.P.; Shrivastav, A.M.; Gupta, B.D. A contemporary approach for design and characterization of fiber-optic-cortisol sensor tailoring LMR and ZnO/PPY molecularly imprinted film. Biosens. Bioelectron. 2017, 87, 178-186. [CrossRef] [PubMed]

44. Usha, S.P.; Gupta, B.D. Urinary p-cresol diagnosis using nanocomposite of $\mathrm{ZnO} / \mathrm{MoS}_{2}$ and molecular imprinted polymer on optical fiber based lossy mode resonance sensor. Biosens. Bioelectron. 2018, 101, 135-145. [CrossRef] [PubMed]

45. Paliwal, N.; John, J. Design and Modeling of Highly Sensitive Lossy Mode Resonance-Based Fiber-Optic Pressure Sensor. IEEE Sens. J. 2018, 18, 209-215. [CrossRef]

46. Ozcariz, A.; Piña-Azamar, D.A.; Zamarreño, C.R.; Dominguez, R.; Arregui, F.J. Aluminum doped zinc oxide (AZO) coated optical fiber LMR refractometers-An experimental demonstration. Sens. Actuators B Chem. 2019, 281, 698-704. [CrossRef]

47. Prieto-Cortés, P.; Álvarez-Tamayo, R.I.; García-Méndez, M.; Durán-Sánchez, M. Lossy Mode Resonance Generation on Sputtered Aluminum-Doped Zinc Oxide Thin Films Deposited on Multimode Optical Fiber Structures for Sensing Applications in the $1.55 \mu \mathrm{m}$ Wavelength Range. Sensors 2019, 19, 4189. [CrossRef]

48. Ozcariz, A.; Dominik, M.; Smietana, M.; Zamarreño, C.R.; Del Villar, I.; Arregui, F.J. Lossy mode resonance optical sensors based on indium-gallium-zinc oxide thin film. Sens. Actuators A Phys. 2019, 290, $20-27$. [CrossRef]

49. Hernáez, M.; Del Villar, I.; Zamarreño, C.R.; Arregui, F.J.; Matias, I.R. Optical fiber refractometers based on lossy mode resonances supported by $\mathrm{TiO}_{2}$ coatings. Appl. Opt. 2010, 49, 3980. [CrossRef]

50. Zhao, W.M.; Wang, Q.; Wang, X.Z.; Li, X.; Jing, J.Y.; Sun, H.Z. Theoretical and experimental research of lossy mode resonance-based high-sensitivity optical fiber refractive index sensors. J. Opt. Soc. Am. B 2019, 36, 2069. [CrossRef]

51. Tien, C.L.; Lin, H.Y.; Su, S.H. High Sensitivity Refractive Index Sensor by D-Shaped Fibers and Titanium Dioxide Nanofilm. Adv. Condens. Matter Phys. 2018. [CrossRef] 
52. Tiwari, D.; Mullaney, K.; Korposh, S.; James, S.W.; Lee, S.W.; Tatam, R.P. An ammonia sensor based on Lossy Mode Resonances on a tapered optical fibre coated with porphyrin-incorporated titanium dioxide. Sens. Actuators B Chem. 2017, 242, 645-652. [CrossRef]

53. Wang, X.Z.; Wang, Q. Theoretical Analysis of a Novel Microstructure Fiber Sensor Based on Lossy Mode Resonance. Electronics 2019, 8, 484. [CrossRef]

54. Wang, X.; Wang, Q.; Song, Z.; Qi, K. Simulation of a microstructure fiber pressure sensor based on lossy mode resonance. AIP Adv. 2019, 9. [CrossRef]

55. Zamarreño, C.R.; Hernáez, M.; Del Villar, I.; Matías, I.R.; Arregui, F.J. Optical fiber pH sensor based on lossy-mode resonances by means of thin polymeric coatings. Sens. Actuators B Chem. 2011, 155, 290-297. [CrossRef]

56. Rivero, P.J.; Goicoechea, J.; Hernaez, M.; Socorro, A.B.; Matias, I.R.; Arregui, F.J. Optical fiber resonance-based $\mathrm{pH}$ sensors using gold nanoparticles into polymeric layer-by-layer coatings. Microsyst. Technol. 2016, 22, 1821-1829. [CrossRef]

57. Rivero, P.J.; Urrutia, A.; Goicoechea, J.; Arregui, F.J. Optical fiber humidity sensors based on Localized Surface Plasmon Resonance (LSPR) and Lossy-mode resonance (LMR) in overlays loaded with silver nanoparticles. Sens. Actuators B Chem. 2012, 173, 244-249. [CrossRef]

58. Urrutia, A.; Goicoechea, J.; Rivero, P.J.; Pildain, A.; Arregui, F.J. Optical fiber sensors based on gold nanorods embedded in polymeric thin films. Sens. Actuators B Chem. 2018, 255, 2105-2112. [CrossRef]

59. Hernaez, M.; Mayes, A.G.; Melendi-Espina, S. Lossy Mode Resonance Generation by Graphene Oxide Coatings onto Cladding-Removed Multimode Optical Fiber. IEEE Sens. J. 2019, 19, 6187-6192. [CrossRef]

(C) 2020 by the authors. Licensee MDPI, Basel, Switzerland. This article is an open access article distributed under the terms and conditions of the Creative Commons Attribution (CC BY) license (http://creativecommons.org/licenses/by/4.0/). 